\title{
Pkcס Activation is Involved in ROS-Mediated Mitochondrial Dysfunction and Apoptosis in Cardiomyocytes Exposed to Advanced Glycation End Products (Ages)
}

\author{
Yao-Chih Yang ${ }^{1}$, Cheng-Yen Tsai ${ }^{2,3}$, Chien-Lin Chen ${ }^{4}$, Chia-Hua Kuo ${ }^{5,6}$, Chien-Wen Hou ${ }^{5}$, Shi- \\ Yann Cheng ${ }^{7,8,9}$, Ritu Aneja ${ }^{10}$, Chih-Yang Huang11,\#, Wei-Wen Kuo",\#,*
}

\begin{abstract}
${ }^{1}$ Department of Biological Science and Technology, College of Biopharmaceutical and Food Sciences, China Medical University, Taiwan. ${ }^{2}$ Department of Pediatrics, China Medical University Beigang Hospital, Taiwan. ${ }^{3}$ School of Chinese Medicine, College of Chinese Medicine, China Medical University, Taiwan. ${ }^{4}$ Department of Life Sciences, National Chung Hsing University, Taiwan. ${ }^{5}$ Laboratory of Exercise Biochemistry, University of Taipei, Taipei, Taiwan. ${ }^{6}$ Graduate Institute of Physical Therapy and Rehabilitation Science, China Medical University, Taiwan. ${ }^{7}$ Department of Medical Education and Research and Department of Obstetrics and Gynecology, China Medical University Beigang Hospital, Taiwan. ${ }^{8}$ Department of Obstetrics and Gynecology, China Medical University An Nan Hospital, Taiwan. ${ }^{9}$ Obstetrics and Gynecology, School of Medicine, China Medical University, Taichung, Taiwan. ${ }^{10}$ Department of Biology, Georgia State University, Atlanta, GA 30303, USA. ${ }^{11}$ Graduate Institute of Basic Medical Science, China Medical University, Taichung, Taiwan; Graduate Institute of Chinese Medical Science, School of Chinese Medicine, China Medical University, Taichung, Taiwan; Department of Health and Nutrition Biotechnology, Asia University, Taichung, Taiwan.
\end{abstract}

[Received June 15, 2017; Revised September 2, 2017; Accepted September 24, 2017]

\begin{abstract}
Diabetic patients exhibit serum AGE accumulation, which is associated with reactive oxygen species (ROS) production and diabetic cardiomyopathy. ROS-induced PKC $\delta$ activation is linked to mitochondrial dysfunction in human cells. However, the role of PKC $\delta$ in cardiac and mitochondrial dysfunction caused by AGE in diabetes is still unclear. AGE-BSA-treated cardiac cells showed dose- and time-dependent cell apoptosis, ROS generation, and selective PKC $\delta$ activation, which were reversed by NAC and rotenone. Similar tendency was also observed in diabetic and obese animal hearts. Furthermore, enhanced apoptosis and reduced survival signaling by AGE-BSA or PKC $\delta$-WT transfection were reversed by kinase-deficient (KD) of PKC $\delta$ transfection or PKC inhibitor, respectively, indicating that AGE-BSA-induced cardiomyocyte death is PKC $\delta$-dependent. Increased levels of mitochondrial mass as well as mitochondrial fission by AGE-BSA or PKC $\delta$ activator were reduced by rottlerin, siPKC $\delta$ or KD transfection, indicating that the AGE-BSA-induced mitochondrial damage is PKC $\delta$ dependent. Using super-resolution microscopy, we confirmed that PKC $\delta$ colocalized with mitochondria. Interestingly, the mitochondrial functional analysis by Seahorse XF-24 flux analyzer showed similar results. Our findings indicated that cardiac PKC $\delta$ activation mediates AGE-BSA-induced cardiomyocyte apoptosis via ROS production and may play a key role in the development of cardiac mitochondrial dysfunction in rats with diabetes and obesity.
\end{abstract}

Key words: advanced glycation end products (AGEs), apoptosis; diabetes mellitus (DM), mitochondrial, protein kinase $\mathrm{C}(\mathrm{PKC}) \delta$, reactive oxygen species (ROS)

Continuous hyperglycemia, a common feature of both type I and type II diabetes mellitus (DM) patients, plays a crucial role in diabetic complications in macrovessel and microvessel structures. A particular target organ in this setting is the heart. The destruction of cardiac function has been well recognized as a result of cardiomyocyte

*Correspondence should be addressed to: Dr. Wei-Wen Kuo, Dept. of Biological Science \& Technology, School of Life Science, China Medical University, Taichung, 40402, Taiwan, ROC. E-mail address: wwkuo@mail.cmu.edu.tw. \# Equal contribution.

Copyright: ( 2017 Yang YC et al. This is an open-access article distributed under the terms of the Creative Commons Attribution License, which permits unrestricted use, distribution, and reproduction in any medium, provided the original author and source are credited. 
apoptosis in both clinical and experimental diabetes [1-3]. Numerous studies have reported that a direct correlation between the pathogenesis of diabetic heart disease and the reactive oxygen species (ROS) production, which is induced by hyperglycemia-derived advanced glycation end products (AGEs) [4, 5]. Therefore, the mechanism through which AGE formation induced by high glucose exposure stimulates ROS generation to cause cardiomyocyte apoptosis needs to be elucidated [6].

AGEs are a heterogeneous group of compounds produced from the non-enzymatic glycation or glycoxidation of proteins, lipids and nucleic acids with carbonyl methylglyoxal (MGO), a major AGE precursor. AGE formation is directly accelerated in chronic high glucose condition and is associated with an increased generation of ROS [7, 8]. Although AGEs in plasma and tissues accumulate slowly during natural aging, they are dramatically elevated in patients with DM, contributing to the development of diabetic complications. In addition, through the association with the receptor for AGE (RAGE), the accumulated AGEs can initiate a cascade of signal transduction to activate several worse outcomes, such as oxidative stress, inflammation and apoptosis, leading to target cell dysfunction [7,8]. Our previous studies $[5,9,10]$ using experimental diabetic rat models showed that hyperglycemia can cause reduced cardiac contraction function evidenced by the decreased ejection fraction and fraction shortening. However, the signaling involved in hyperglycemia-derived AGEs induced cardiac apoptosis need to be further identified.

Protein kinase $\mathrm{C} \delta(\mathrm{PKC} \delta)$, a member of the novel PKC subfamily, is involved in cell apoptosis in a stimulusand tissue-specific manner; it regulates the expression and function of apoptotic-related proteins and is itself a target for caspases [11-13]. Activation of $\mathrm{PKC} \delta$ by various apoptotic stimuli results in the translocation of PKC $\delta$ to distinct cellular compartments. For example, PKC $\delta$ activation during reperfusion results in translocation to the mitochondria where it can negatively regulate mitochondrial function and initiate pro-apoptotic pathways by direct effects on mitochondria [14-16]. Additionally, it is reported that $\mathrm{PKC} \delta$ is phosphorylated in cells treated with $\mathrm{H}_{2} \mathrm{O}_{2}$ [17]. Moreover, $\mathrm{H}_{2} \mathrm{O}_{2}$-induced apoptosis is blocked by the inhibition of PKC activation and translocation to the mitochondria [18], indicating that ROS-induced cell apoptosis may be dependent on PKC $\delta$ activation and mitochondria translocation.

It has been reported that aberrant mitochondrial dynamic and degeneration in cardiac disorder induced by high glucose-derived ROS is associated with cardiomyocyte apoptosis [19]. The $\mathrm{PKC} \delta$ activation is involved in ROS-mediated mitochondrial dysregulation [20]. Because the hearts are particularly responsive to the changes in mitochondria function due to their high energy demands [19], the triggers for this cardiac mitochondrial dysfunction to further cause cell death are needed to be revealed. Therefore, here is the study to identify whether ROS-mediated PKC $\delta$ activation is involved in AGEinduced cardiac mitochondrial dysfunction and cell apoptosis to cause heart failure.

Actuarially, several studies have identified the involvement of PKC isoforms in pathogenesis of heart disease, including diabetic cardiomyopathy [21, 22]. However, very little work focused on the association of $\mathrm{PKC} \delta$ activated mitochondrial dysregulation with heart diseases, such as diabetic cardiac disorder. In this study, we investigated the role of PKC $\delta$ in AGE-induced cardiac apoptosis in vitro and in vivo. We found that $\mathrm{PKC} \delta$ was dose-dependently activated in cardiomyocytes administered with AGEs, and AGEs also induced cardiac mitochondrial fission and cell apoptosis. We identified a regulatory pathway for AGE-induced apoptosis through PKC $\delta$ activation. The results on PKC $\delta$ activation suggest a target to protect cardiomyocytes against AGE-induced apoptosis for the treatment of diabetic cardiomyopathy.

\section{MATERIAL AND METHODS}

\section{Cell culture}

H9c2 cardiomyoblast cells derived from embryonic BD1X rat heart tissue were obtained from American Type Culture Collection (ATCC ${ }^{\circledR}$ CRL-1446 ${ }^{\mathrm{TM}}$, Manassas, VA, USA), and cultured in Dulbecco's modified eagle's medium (DMEM, 12100-046; Gibco, Grand Island, NY, USA) with $10 \%$ fetal bovine serum (FBS; Hyclone, U.S.), Penicillin-Streptomycin (Pen/Strep, 15140122; Gibco BRL, Paisley, Scotland, USA) in a humidified atmosphere containing $5 \% \mathrm{CO}_{2}$ at $37{ }^{\circ} \mathrm{C}$. Experiments on $\mathrm{H} 9 \mathrm{c} 2$ cells were performed with $80 \%$ confluent cells that had been seeded in 100-mm.

\section{Neonatal rat ventricular myocytes primary culture}

NRVMs were prepared and cultured using a Neonatal Rat/Mouse Cardiomyocyte Isolation Kit (nc-6031; Cellutron Life Technology, Baltimore, MD, USA) which was previously described [23]. Hearts were dissected from 1- to 3-day-old Sprague-Dawley rats and transferred into a sterile beaker. Each heart was digested and stirred in the beaker at $37^{\circ} \mathrm{C}$ for $12 \mathrm{~min}$. The supernatant was then transferred to a new sterile tube and spun at 1200 r.p.m. for $1 \mathrm{~min}$. The cell pellets were then resuspended in D3 buffer and pre-plated for $1 \mathrm{~h}$ by seeding on an uncoated plate at $37^{\circ} \mathrm{C}$ in a $\mathrm{CO}_{2}$ incubator to select the cardiac fibroblasts. The unattached cells were 
transferred onto plates that were precoated with NS medium (supplemented with 10\% fetal bovine serum). After overnight culture, the NS medium was replaced with a serum-free NW (without serum) medium. The cardiomyocyte cultures were ready for experiments $48 \mathrm{~h}$ after the initial plating.

\section{Glucose derived-AGE preparation}

AGEs were prepared according to methods described previously [24-26]. AGE was prepared by incubating bovine serum albumin (A8806, BSA, fraction V, fatty acid-free, endotoxin-free; Sigma Chemical, $100 \mathrm{mg} / \mathrm{mL}$ ) with D-glucose $(1 \mathrm{M})$ in dulbecco's phosphate buffered saline (DPBS, 21600-010; Gibco) for 12 weeks at $37^{\circ} \mathrm{C}$. Unmodified BSA was prepared under the same conditions without glucose as a control. Fluorescence of the supernatant was determined (excitation $370 \mathrm{~nm}$, emission $440 \mathrm{~nm}$ ) using LJL Biosystems (AnalystTM AD, Sunnyvale, CA, USA), which confirmed the higher intensity of AGE in AGE-modified BSA than that in unmodified BSA (Suppl. Fig. S10). The AGE solution was filtered to be sterile by $0.8 \mu \mathrm{M}$ Millex GP filter unit (Millipore, Billerica, MA, USA).

\section{MTT assay for cell viability}

Cell viability was measured using the MTT assay as previously described [27], and based on the 3-(4, 5Dimethylthiazol-2-yl)-2, 5-diphenyltetrazolium bromide (MTT, M2003; Sigma, St. Louis, MO, USA) conversion into formazan crystals using mitochondrial dehydrogenases. The prepared $\mathrm{H} 9 \mathrm{c} 2$ cells suspension was seeded into 96 -well plates at a density of $1 \times 10^{4}$ cells/well and incubated at $37{ }^{\circ} \mathrm{C}$ for $24 \mathrm{~h}$. Then the cells were treated with $(0-300 \mu \mathrm{g} / \mathrm{ml})$ AGEs as indicated for $(0-36 \mathrm{~h})$. The supernatant was discarded and the culture medium was replaced with $100 \mu \mathrm{l}$ of MTT solution $(5 \mathrm{mg} / \mathrm{ml}$ stock solution in DPBS, diluted with culture medium to the final concentration $0.5 \mathrm{mg} / \mathrm{ml}$ ) was added into each well. Then the cells were maintained at $37^{\circ} \mathrm{C}$ for $4 \mathrm{~h}$, this solution was removed and the formed formazan was dissolved with $100 \mu \mathrm{l}$ dimethyl sulfoxide (DMSO). The optical density (O.D.) values of samples were read at $580 \mathrm{~nm}$ with a micro plate reader.

\section{Reactive oxygen species production}

Intracellular generation of ROS was examined by peroxide-sensitive fluorescent probe 2', 7'-dichlorofluorescein diacetate (CM-H2 DCFH-DA, C6827; Molecular Probes, Invitrogen, Carlsbad, CA, USA) as previously described [10], the fluorescent dichloro- fluorescein (DCF) formed by oxidation of DCFH was quantified by flow cytometry. Briefly, cells were incubated with $(5 \mu \mathrm{M}) \mathrm{CM}-\mathrm{H} 2 \mathrm{DCFDA}$ for $30 \mathrm{~min}$ at 37 ${ }^{\circ} \mathrm{C}$ in dark. The following inhibitors were used the ROS scavenger, N-acetyl-L-cysteine (NAC, $500 \mu \mathrm{M}$, Sigma, St. Louis, MO, USA); the Mitochondrial Complex I inhibitor Rotenone $(0.1 \mu \mathrm{M}$, Sigma, St. Louis, MO, USA). Additionally, mitochondrial superoxide $\left(\mathrm{O}_{2}\right.$ radical $\left.\operatorname{dot}^{-}\right)$ was evaluated by MitoSOX ${ }^{\mathrm{TM}}$ Red mitochondrial superoxide indicator (M36008, Molecular Probes, Invitrogen, Eugene, OR, USA). Cells were resuspended with MitoSOX ${ }^{\mathrm{TM}}(2 \mu \mathrm{M})$ and allowed to incubate at $37^{\circ} \mathrm{C}$ for 10-15 min. Samples were analyzed by a BD FACSCantoM II flow cytometer (Becton-Dickinson, Franklin Lakes, NJ) to identify mean mitochondrial ROS production.

\section{Transfection of plasmid DNA and siRNA assay}

Cells with $50 \%$ confluence were replaced into fresh culture medium containing serum then plasmid of pEGFP N1-PKC $\delta$ (GFP-PKC $\delta$-WT) and pEGFP N1-PKC $\delta^{\mathrm{K} 376 \mathrm{R}}$ (GFP-PKC $\delta$-KD; PKC $\delta$ kinase dominant negative mutant) which were obtained from Department of Life Science and the Graduate Institute of Biomedical Sciences, National Chung Hsing University, Dr. H.C. Chen lab [28], were transfected in the cells AGE or not for 24 hours using PureFection $^{\mathrm{TM}} \quad$ Nanotechnology-based Transfection Reagent (System Biosciences, Inc., Mountain View, CA, USA) following the manufacture protocol. Doublestranded si-RNA sequences targeting PKC $\delta$ mRNAs were obtained from EMD Millipore Corporation. Then nonspecific si-RNA (scramble) consisted of a non-targeting double-stranded RNA. Cells were cultured in 100-mm plates in medium. Transfection of si-RNA was carried out with transfection reagent. Specific silencing was confirmed by immunoblotting with cellular extracts after transfection.

\section{Determination of mitochondrial mass}

Mitochondrial mass was measured with the fluorescent dye nonyl acridine orange (NAO, Molecular Probes; Invitrogen, Eugene, OR, USA), which binds to cardiolipin in mitochondrial inner membrane. The cells at subconfluent stage were trypsinized and resuspended in $0.5 \mathrm{ml}$ of DPBS containing $2.5 \mu \mathrm{M}$ NAO. After incubation for $15 \mathrm{~min}$ at $25^{\circ} \mathrm{C}$ in the dark, cells were immediately transferred to a tube for analysis on a flow cytometry (Becton-Dickinson FACSCanto, Franklin Lakes, NJ). The excitation wavelength was set at $488 \mathrm{~nm}$ and the intensity of emitted fluorescence of a total of 10,000 cells at $525 \mathrm{~nm}$ was recorded on channel FL1. 


\section{Animal model and treatments}

Male Wistar rats (four-week old) were purchased from the National Animal Breeding and Research Center (Taipei, Taiwan). All the animals were maintained under a 12-h light/dark cycle at a constant temperature $\left(25^{\circ} \mathrm{C}\right)$ and were provided access to water and standard laboratory chow (Lab Diet 5001; PMI Nutrition International Inc., Brentwood, MO, USA). Room conditions and experimental procedures were followed according to the NIH Guide for the Care and Use of Laboratory Animals and all protocols were approved by the Institutional Animal Care and Use Committee of China Medical University, Taichung, Taiwan. The animals were arranged into two groups ( $\mathrm{n}=5$ each): Wistar rats, Wistar rats received of intraperitoneal (IP) streptozotocin (STZ; Sigma, St. Louis, MO). After one week of acclimatization, diabetes was induced by the injecting STZ $(65 \mathrm{mg} / \mathrm{kg}$ body weight in a citrate buffer, $\mathrm{pH} 4.5$ ) into a lateral tail vein. After three days of injection, glucose level was measured with the Accu-Check Compact kit (Roche Diagnostics Gmbh, Mannheim, Germany). Sixteen days after treatment the animals were sacrificed and hearts were removed for further analysis. All 12 male SD hamsters (eight weeks old, $300 \mathrm{~g}$ weight) were purchased from BioLASCO Taiwan Co., Ltd. (Taipei, Taiwan) and divided into two groups ( $\mathrm{n}=6$ each). The control hamster group was labeled as control. The high-fat diet treatment hamster group was labeled as HFD.

\section{Western blot analysis}

The protein levels of cultured cells were performed as previously described [27]. Cultured H9c2 cell were scraped and washed twice with DPBS, then cell suspension was spun down, and cell pellets were lysed for $30 \mathrm{~min}$ in lysis buffer $(50 \mathrm{mM}$ Tris $(\mathrm{pH} 7.5), 0.5 \mathrm{M} \mathrm{NaCl}$, $1.0 \mathrm{mM}$ EDTA ( $\mathrm{pH} 7.5$ ), $10 \%$ glycerol. Spin down in $12,000 \mathrm{rpm}$ for 30 minutes then the supernatant was collected. Protein samples were separated in $8 \sim 10 \%$ SDSPAGE and transferred to polyvinylidene difluoride (PVDF; Millipore, Billerica, MA, USA) membranes. Nonspecific protein binding was prohibited by a blocking buffer $(5 \%$ milk, $20 \mathrm{mM} \mathrm{pH} 7.6$ Tris- $\mathrm{HCl}, 150 \mathrm{mM} \mathrm{NaCl}$, and $0.1 \%$ Tween-20) and the proteins were blotted with specific antibodies in the blocking buffer at $4{ }^{\circ} \mathrm{C}$ overnight. After incubations with a secondary antibody for $2 \mathrm{~h}$, the densitometry of immunoblots was analyzed by Fuji LAS 3000 imaging system. Primary antibodies $\mathrm{PKC} \delta, \theta, \zeta$, Caspase-3, Cleaved Caspase-3, Caspase-9, Cleaved Caspase-9, COX IV, Phospho-DRP1, Phospho-PKC $\theta$, $\zeta$, p62/SQSTM1, LC3B (\#2058, \#2059, \#9368, \#9665s, \#9664, \#9506, \#9507, \#11967, 3455s, \#9377, \#2060,
\#5114, \#2775, Cell signaling), PKCa, Phosphor- PKCa (05-154, 06-822, Upstate), Phospho-PKC $\delta$ T505/507 (\#9374, Cell signaling, NBP1-51405, Novus, bs-3727R, Bioss), $\beta$-Actin, Phospho-Akt, Bcl2, Bax, Bcl XL Bak, Cytochrome $C$,DRP1, GFP, Parkin, PINK1 (sc-47778, sc7985, sc-7382, sc-526, sc-8392, sc-7873, sc-13560, sc32898, sc-8334, sc- 30130, sc-33796, Santa Cruz).

\section{Immunohistochemistry}

The examination of $\mathrm{PKC} \delta$ protein in cardiac tissues was performed as previously described [29]. The tissue sections were deparaffinized and rehydrated. After three washes in DPBS, we then used $1 \%$ bovine serum albumin to block nonspecific binding. Then the sections were incubated with primary antibody against $\mathrm{PKC} \delta(1: 100$ dilution; bs-3727R; Bioss) at $4^{\circ} \mathrm{C}$ overnight in a moist chamber. Blocking solution without the primary antibody was used as a negative control. After being incubated with horseradish peroxidase for 30 minutes at $37^{\circ} \mathrm{C}$, the slides were incubated with 3,3'-diaminobenzidine (DAB; Sigma) solution for visualization. After washing by PBS fir 10 minutes the tissue microarray was then detected by using microscopy (magnification: 200X) (Olympus, Tokyo japan). Primary antibody Phospho-PKC $\delta$ T505/507 (bs3727R; Bioss).

\section{Indirect immunofluorescence and confocal microscopy}

We carried out mitochondrial staining as described [30]. Expression of phosphorylation $\mathrm{PKC} \delta$ protein was analyzed on cells with a Leica TCS SP2 confocal microscope using a monoclonal Phospho-PKC $\delta$ Thr505/507 (bs-3727R, Bioss) antibody. Briefly, we plated the cells $\left(1 \times 10^{4}\right)$ onto the chamber slide. After treatment, we stained them for $20 \mathrm{~min}$ with $0.02 \mu \mathrm{M}$ MitoTracker Red CMXRos (M7510; Molecular probes, Invitrogen, Grand Island, NY, USA). Cells were fixed with 4\% paraformaldehyde (Sigma-Aldrich, St. Louis, $\mathrm{MO}$ ) for $15 \mathrm{~min}$ at room temperature and permeabilized with $0.1 \%$ Triton X-100 (Merck, Germany) for $15 \mathrm{~min}$ at room temperature before staining with a specific antibody. Then, the cells were washed and stained with Alexa 546 rabbit anti-mouse $\operatorname{IgG}$ secondary antibodies (A-11060; Invitrogen, Carlsbad, CA, USA) for 2 hours at $37^{\circ} \mathrm{C}$, and rinsed and mounted. The cellular nuclei were stained by 4', 6-diamidino-2-phenylindole (DAPI; Sigma, St. Louis, MO, USA). Images were captured using a Leica SP2 Confocal Spectral Microscope (Buffalo Grove, IL, USA). The images were processed using Adobe Photoshop.

\section{N-SIM: Nikon-structured illumination microscope}


Samples were essentially prepared as before the confocal experiment. Super-resolution imaging was performed with a Nikon-structured illumination microscope (N-SIM) system equipped with a CFI Plan Apochromat IR 60x WI DIC N2 (NA 1.27) immersion objective and an iXon3 camera (DU-897 X-5472, Andor Technology). 3D-SIM image stacks were acquired with a Z-distance of $0.2 \mu \mathrm{m}$, covering the entire thickness of the cell (about $3.1 \mu \mathrm{m}$ ). The camera settings were configured as follows: format for capture, no binning; exposure time, $150 \mathrm{~ms}$ (1 frame recommended); readout mode, EM gain $10 \mathrm{MHz}$ 14-bit; gain multiplier, 20-200 ms (max 300); conversion gain. $5.1 \times 15$ raw images per plane were acquired and computationally reconstructed using the reconstruction slice system from NIS-Elements software (Nikon).

\section{Immunoprecipitation}

Immunoprecipitations were performed using H9c2 cell lysates and the PureProteome Protein G Magnetic Bead System (Millipore) according to the manufacturer's instructions. The total cell lysates $(500 \mu \mathrm{g})$ for each sample were specifically bond with $5 \mu \mathrm{g}$ of a specific primary antibody, and the mixture was incubated on a rotator at $4^{\circ} \mathrm{C}$ overnight. The immunoprecipitates were collected by centrifugation at $2,500 \mathrm{rpm}$ for $5 \mathrm{~min}$ at $4{ }^{\circ} \mathrm{C}$, supernatants were discarded and pellet was resuspended with $2 \times$ electrophoresis sample buffer by boiling at $95^{\circ} \mathrm{C}$ for $10 \mathrm{~min}$ and separated by SDS-PAGE.

\section{Mitochondria isolation}

Mitochondria were isolated using a mitochondria isolation kit (Thermo Scientific, Rockford, IL, USA) according to the manufacturer's instructions. Mitochondrial subpopulation pellets were resuspended in sucrose-based SEM buffer $(250 \mathrm{mM}$ sucrose, $1 \mathrm{mM}$ EDTA, and $10 \mathrm{mM}$ MOPS, pH 7.2) depending on the assay to be performed. Mitochondrial protein concentrations were determined using the Bradford method as a standard, and analyzed by western blotting.

\section{Measurement of bioenergetic parameters}

To determine cellular oxygen consumption rate (OCR) and extracellular acidification rate (ECAR) of the primary culture of NRVMs and H9c2, we used the XF24 Analyzer (Seahorse Bioscience, North Billerica, MA, USA). Briefly, a seeding density of $1.5 \times 10^{4}$ cells per well in 200-500 $\mu 1$ growth medium on an XF24-well microplate (Seahorse Bioscience) were adhered and incubated at $37{ }^{\circ} \mathrm{C}$, then after treatment the culture medium was replaced $1 \mathrm{~h}$ prior to measurement by the assay medium pre-warmed to $37^{\circ} \mathrm{C}$
( $\mathrm{pH}$ 7.4). The program of Seahorse XF24 Analyzer was set according to the manufacturer's recommendation and the data are expressed in $\mathrm{pmol} / \mathrm{min} / 10^{4}$ cells for OCR and in $\mathrm{mpH} / \mathrm{min} / 10^{4}$ cells for ECAR to allow comparison between independent experiments. The OCR and ECAR reflect the metabolic activities of the cells and the numbers of cells, therefore the values were normalized to the total amount of cells in each well.

\section{Statistical analysis}

All experiments data were performed from three individual experiments and presented as mean \pm S.E.M. One-way ANOVA was performed to compare the statistical difference of all groups. The level of $p<0.05$ was considered statistically significant.

\section{RESULTS}

\section{Effects of AGE-BSA treatment on cell viability, apoptosis and ROS generation}

Cells were cultured with AGE-BSA or non-glycated BSA, and cell viability was determined at 3, 6, 12, 24, $36 \mathrm{~h}$ after AGE exposure (Fig 1A). AGE-BSA time-dependently decreased cell viability compared to control at $24 \mathrm{~h}$. However, treatment with bovine serum albumin (BSA) and AGE-BSA time 0 (T0) did not significantly change cell growth $(P>0.05)$. The analysis results of apoptotic proteins as shown in Fig. 1(B \& C) (Suppl. Fig. S1), AGEBSA significantly increased cleaved caspase-9, cleaved caspase-3 and cleaved PARP levels. In contrast, AGEBSA markedly reduced Akt phosphorylation and Bcl-2 survival protein levels (Fig. 1D). These data suggest that AGE-BSA-induced cell apoptosis was associated with proteins related to mitochondria-dependent apoptosis (Suppl. Fig. S9).

To examine the ROS production, the mean fluorescence intensities (MFIs) were measured using $2^{\prime}, 7^{\prime}$-Dichlorofluorescin diacetate (DCFH-DA) and mitochondrial superoxide (MitoSox) Red. As shown in Fig. 1E (Suppl. Fig. S8), cardiac cells dose-dependently increased cellular ROS production compared to control. This increase was attenuated by $\mathrm{N}$-acetyl-L-cysteine (NAC) $(500 \mu \mathrm{M})$ and the mitochondrial complex I inhibitor, rotenone (Rote) $(0.1 \mu \mathrm{M})$.

As shown in Fig. 1(F), after treatment with 100 or $300 \mu \mathrm{g} / \mathrm{ml}$ AGE-BSA for 12 or $24 \mathrm{~h}$, mitochondrial ROS production was increased in a dose- and time-dependent manner. These results indicated that AGE-BSA significantly increased intracellular ROS and mitochondrial-derived superoxide generation. 
A

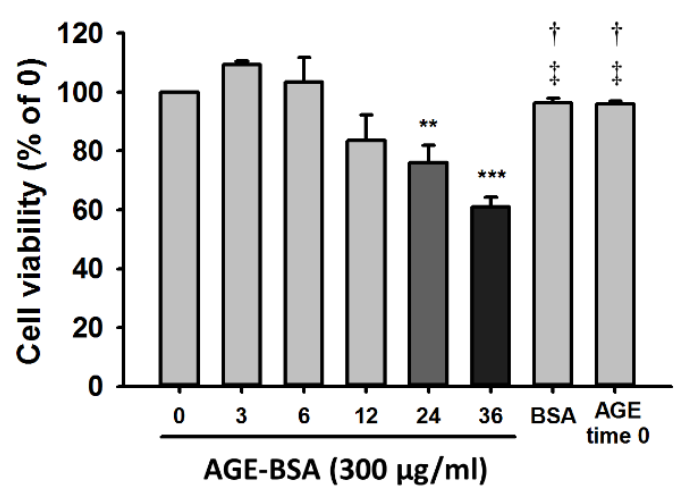

C

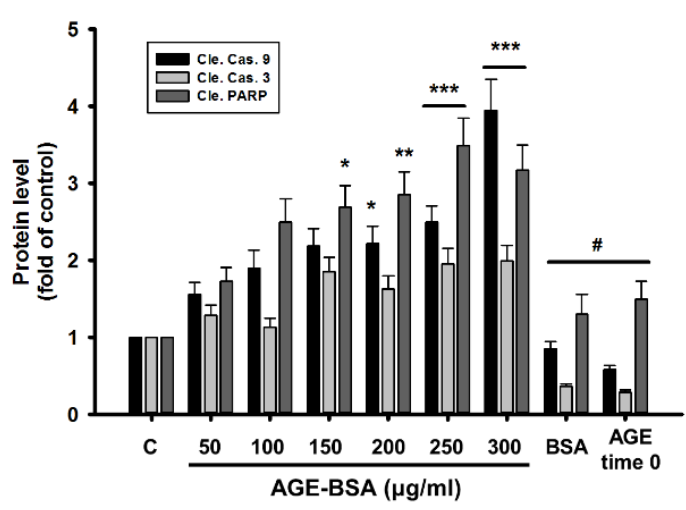

$\mathbf{E}$

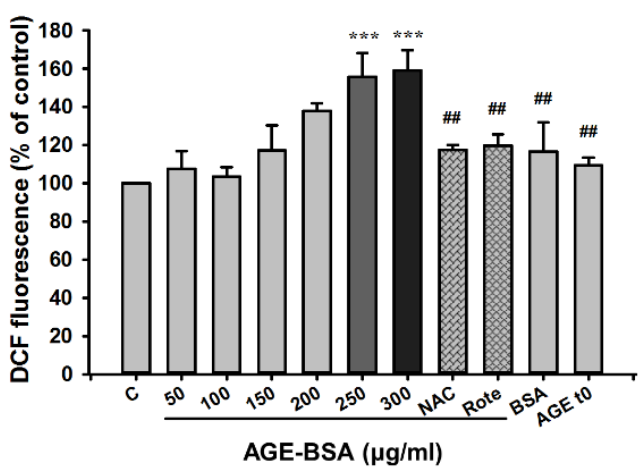

B

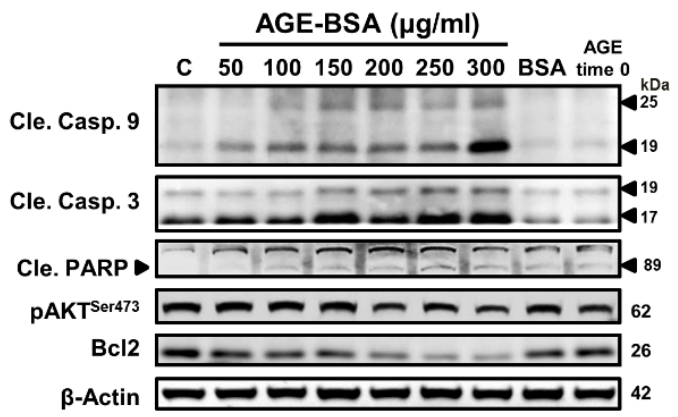

D

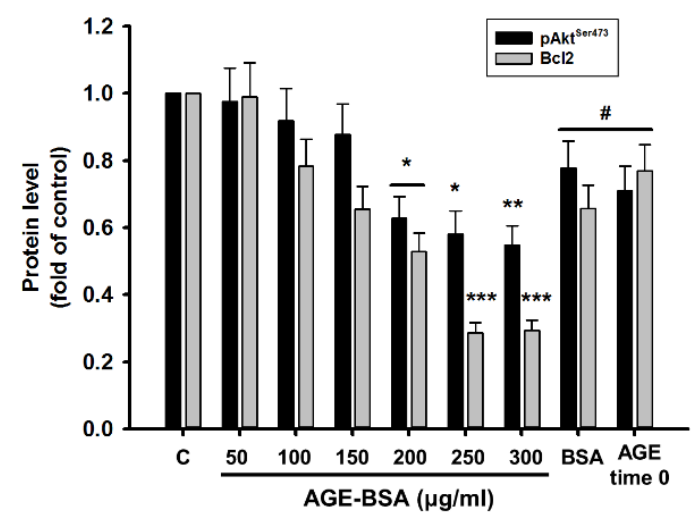

$\mathbf{F}$

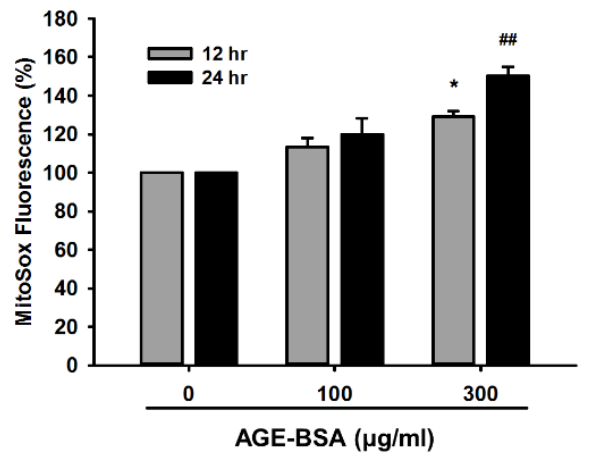

Figure 1. AGE-BSA reduces cell viability, enhanced apoptosis and ROS generation in H9c2 cells in a time- and dosedependent manner. (A) Cells were treated with $300 \mu \mathrm{g} / \mathrm{ml}$ of AGE-BSA for different time periods as indicated or non-glycated BSA. Cell viability was determined using MTT assays. (B) Cells were treated with AGE-BSA at different concentrations as indicated. Levels of apoptosis-related proteins were analyzed by western blotting. These are cropped blots; full-length blots are presented in Suppl. Figure S1. (C, D) Bar graphs show relative optical densities of the (fig. 1B) apoptosis and survival protein levels at $24 \mathrm{~h}$. (E) Intracellular ROS levels of fluorescence intensities of DCF and (F) the mitochondrial ROS levels of AGEBSA-exposed cardiac cells at the indicated doses and time periods were examined by flow cytometry. NAC (500 $\mu \mathrm{M})$; rotenone (Rote) $(0.1 \mu \mathrm{M})$. Bars indicate the mean \pm SEM obtained from experiments performed in triplicate. ${ }^{*} P<0.05,{ }^{* *} P<0.01$ and ${ }^{* * *} P<0.001$ compared with the control group; ${ }^{\#} P<0.05$ and ${ }^{\# \#} P<0.01$ compared with the $300 \mu \mathrm{g} / \mathrm{mg}$ group; ${ }^{\dagger} P<0.05$ when compared with $24 \mathrm{~h}$ or $36 \mathrm{~h}$. 


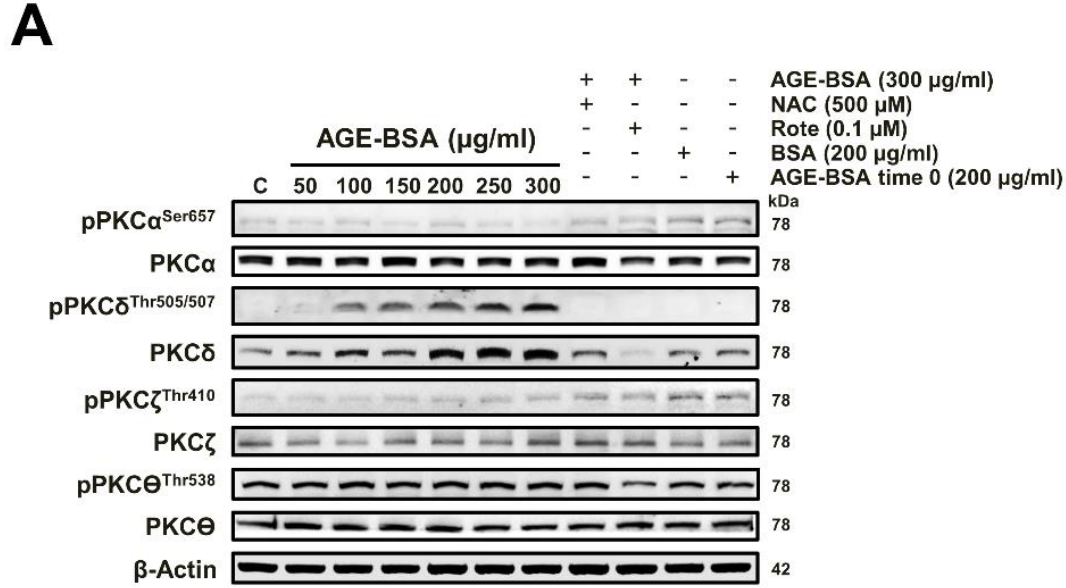

B

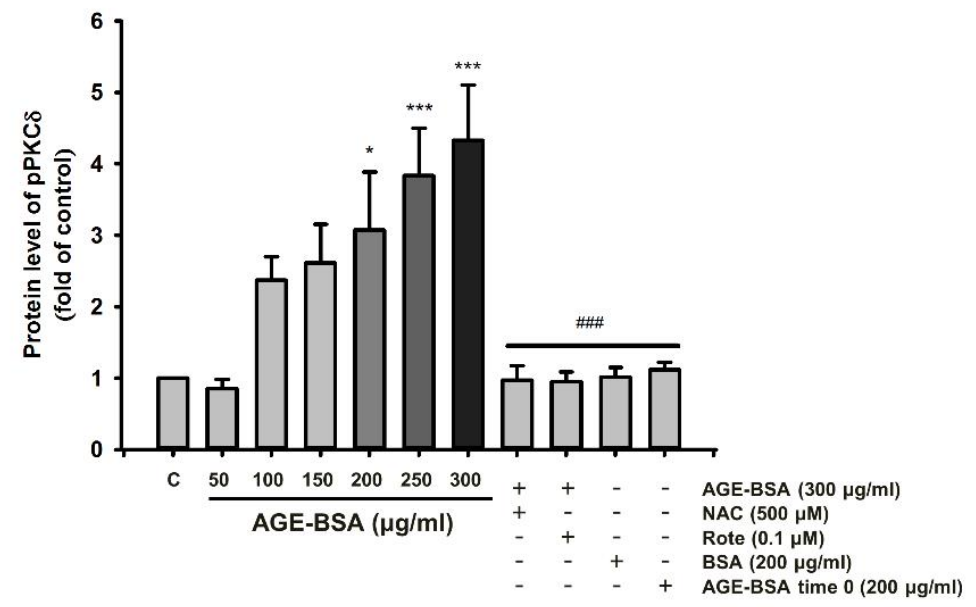

Figure 2. Among PKC isoforms, AGE-BSA specifically induces PKC $\delta$ protein expression and phosphorylation in cardiac cells. (A) Cells were treated with different doses of AGE-BSA with or without ROS scavengers (NAC) and mitochondrial complex I inhibitor (Rote) as indicated for $24 \mathrm{~h}$. Western blot analyses were performed with antibodies against the PKC isoforms. These are cropped blots; full-length blots are presented in Suppl. Figure S2. (B) The densitometry measurements show the quantitative results of the western blots.

Bars indicate the mean \pm SEM obtained from experiments performed in triplicate. ${ }^{*} P<0.05$ and ${ }^{* * *} P<0.001$ compared with the control group; ${ }^{\# \#} P<0.001$ compared with the AGE-BSA $(300 \mu \mathrm{g} / \mathrm{ml})$ group.

\section{Cardiac PKC $\delta$ expression and phosphorylation and apoptosis-related proteins in diseased animal models with elevated AGE levels}

To investigate whether the AGE-BSA can induce the $\mathrm{PKC} \delta$ and $\mathrm{PKC} \delta$ phosphorylation which is mediated through ROS, cells were treated with different doses of AGE-BSA, and western blotting was performed. As shown in Fig. 2(A \& 2B) (Suppl. Fig. S2), the results demonstrated that the total and phosphorylated protein levels of PKC $\delta$ rather than other isoforms were dosedependently increased in cardiac cells treated with AGEBSA $(0-300 \mu \mathrm{M})$ for $24 \mathrm{~h}$. This increase was reduced by the treatments of NAC and rotenone.

To determine the expression profile of PKC family proteins in diseased animal hearts, the protein levels were analyzed and the results showed that cardiac PKC $\delta$ and its phosphrylation rather than other PKC isoforms were induced in the diabetic and aging high-fat (HF) diet- treated rat hearts (Fig. 3A \& B) (Suppl. Fig. S3). Furthermore, an increase in apoptotic protein indicates that AGE-BSA induced apoptosis in AGE-BSA exposed cells (Fig. 1B). Western blot analysis of left ventricles from Diabetes mellitus (DM) rats and high-fat (HF) hamsters revealed a similar trend in p-Akt, cytochrome $C$ and caspase- 3 levels, indicating the development of apoptosis associated with cardiac dysfunction. The echo cardiographic analysis of experimental diabetic hearts demonstrated the reduced cardiac function evidenced by decreased ejection fraction and fraction shortening (Data was shown in our previous studies $[5,9,10]$.) The serum AGE levels were measured with a spectrometer and increased in diseased animals (Fig 3C \& 3D). As shown in Fig. 3(E), we also characterized AGE-BSA-exposed cells using Immunohistochemistry (IHC) with antibodies against pPKC $\delta$ Threonine (Thr) 505/507, which was significantly higher in diseased animal hearts. These results were consistent with those from western blotting. 
A

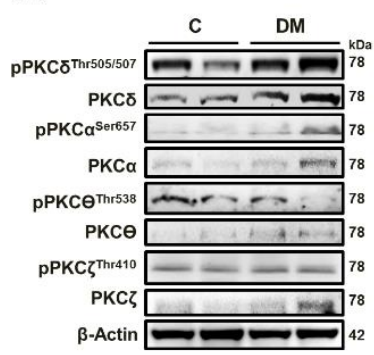

C

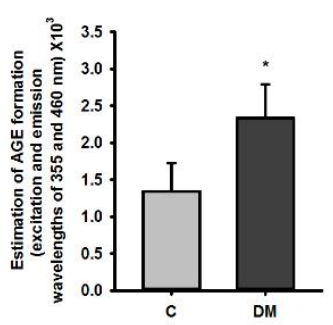

$\mathbf{E}$

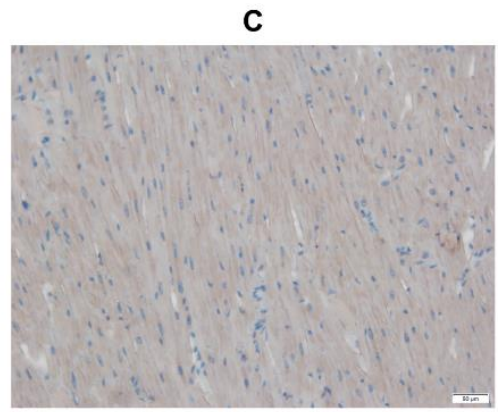

B

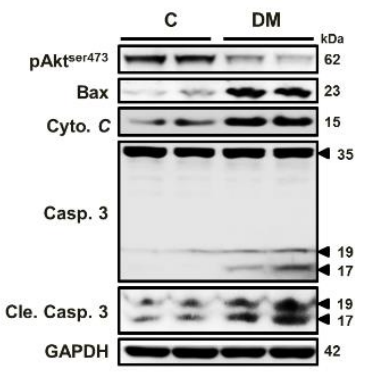

D

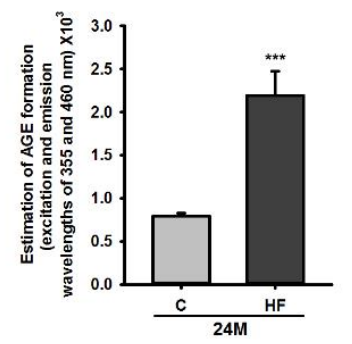

DM

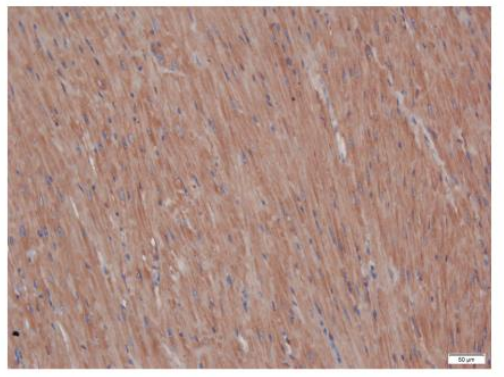

$24 \mathrm{M}$
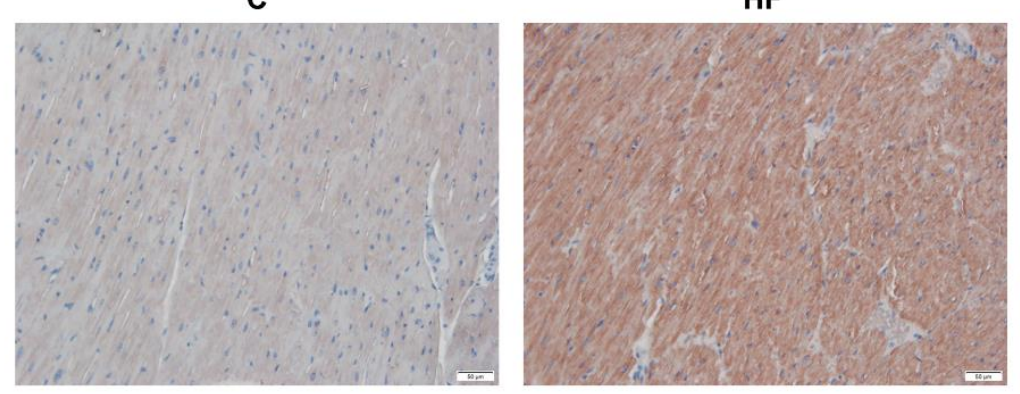

Figure 3. Cardiac PKCס expression and phosphorylation as well as apoptosis-related proteins are increased in diseased animal models with elevated circulatory AGE levels. Western blot analysis of the cardiac expression and phosphorylation levels of PKC isoforms and apoptosis-related proteins in rats with (A) diabetes mellitus (DM) and (B) a high-fat (HF) diet. Serum AGE levels in rats with (C) DM; (D) HF diet. These are cropped blots; full-length blots are presented in Suppl. Figure S3. Protocols for animal models with DM and HF diets and serum AGE analysis were described in the methods section. (E) Cardiac expression of phosphorylated $\mathrm{PKC} \delta$ was examined by immunohistochemistry analysis. Bars indicate the mean \pm SEM obtained from experiments performed in triplicate. ${ }^{*} P<0.05$ and ${ }^{* * *} P<0.001$ compared with the control group. DM, Diabetes mellitus; HF, high-fat diet. 
A

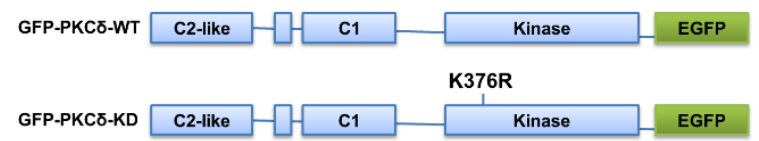

C

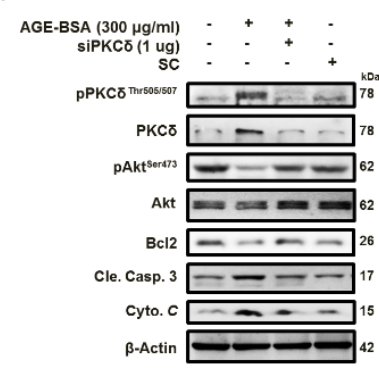

E

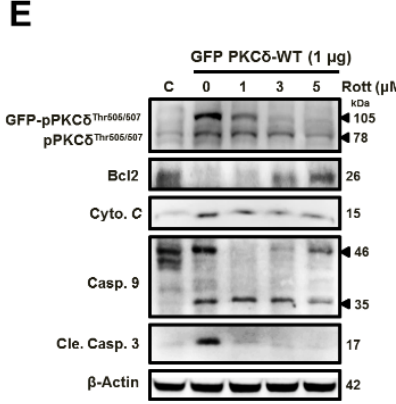

H
D

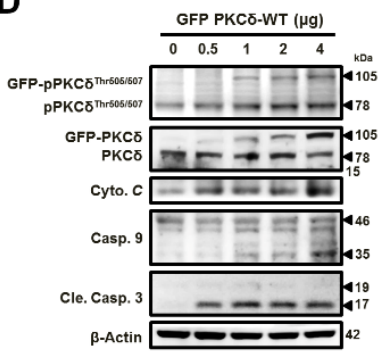

$\mathbf{F}$

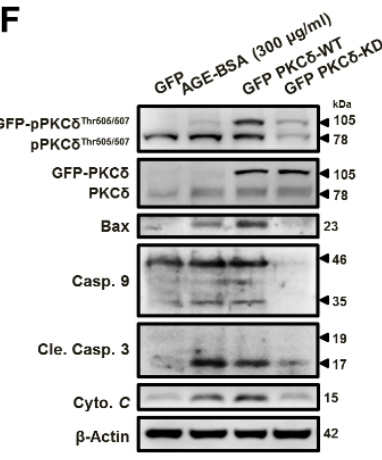

NRVM

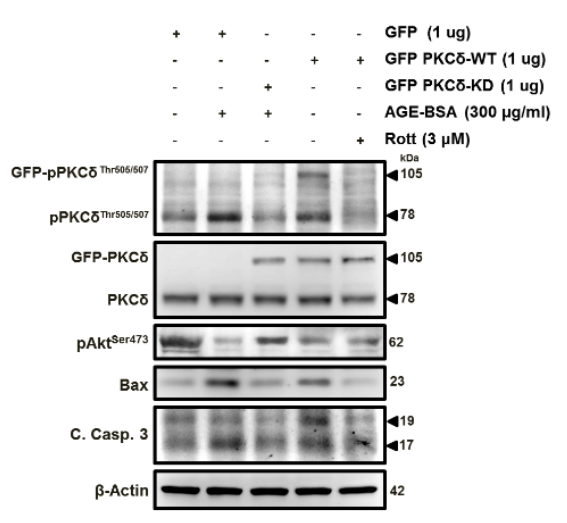

B

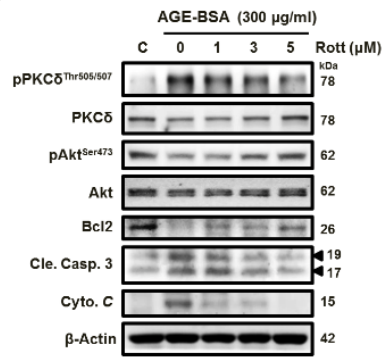

G

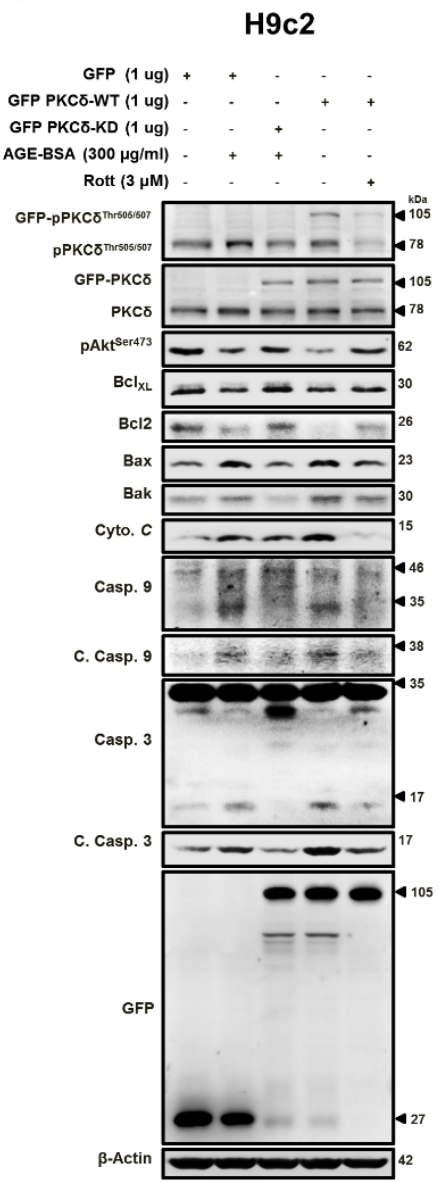

Figure 4. AGE-BSA-induced cardiomyocyte apoptosis is mediated through PKC $\delta$ activation. (A) The diagram depicts the domain organization of GFP-PKC $\delta$. The GFP-PKC $\delta$ derivatives, including the wildtype (WT) and the kinase-deficient mutant (KD; K376R). Cells were treated with AGE-BSA (300 $\mu \mathrm{g} / \mathrm{ml})$ and (B) rottlerin $(1-5 \mu \mathrm{M})$ or $(\mathbf{C})$ PKC $\delta$ silencing. (D) Cells were transfected with GFP-fused PKC $\delta$ (GFP PKC $\delta$-WT) at different doses as indicated and with (E) $1 \mu \mathrm{g}$ rottlerin $(1-5 \mu \mathrm{M})$. (F\&G) H9c2 cells or (H) neonatal rat ventricular myocytes (NRVM) were exposed to AGEs $(300 \mu \mathrm{g} / \mathrm{ml})$ with or without (GFP PKC $\delta$ $\mathrm{KD})$ transfection or transfected with GFP PKC $\delta$-WT in the presence of rottlerin $(3 \mu \mathrm{M})$ or not. These are cropped blots, full-length blots of PKC $\delta$ and pPKC $\delta$ are presented in Suppl. Figure S4. SC, scramble; WT, wild type; KD, kinase-deficient; All the proteins were analyzed by western blotting using $\beta$-actin as a loading control. 


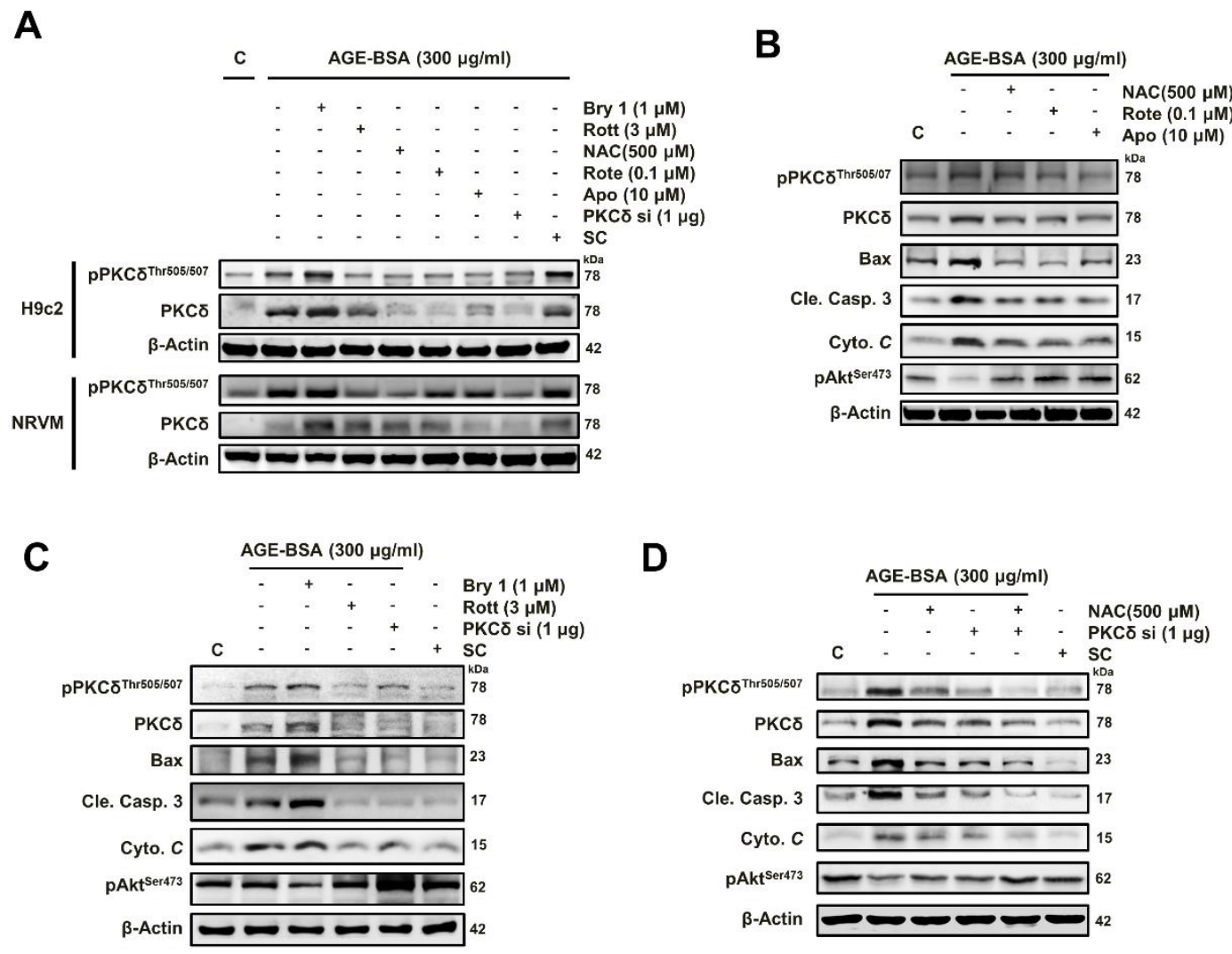

Figure 5. AGE-BSA-induced cardiomyocyte apoptosis is mediated through ROS-dependent PKCס activation. NRVM and $\mathrm{H} 9 \mathrm{c} 2$ cells were exposed to AGE-BSA $(300 \mu \mathrm{g} / \mathrm{ml})$ for $24 \mathrm{~h}$. Cells were co-treated with bryostatin 1, a PKC $\delta$ activator $(100 \mathrm{nM})$, rottlerin, a PKC $\delta$ inhibitor $(3 \mu \mathrm{M})$, NAC $(500 \mu \mathrm{M})$, Rote $(0.1 \mu \mathrm{M})$, Apo $(10 \mu \mathrm{M})$ or siPKC $\delta(1 \mu \mathrm{g})$. (A) Expression and phosphorylation of PKC $\delta$ and $(\mathbf{B}, \mathbf{C}, \mathbf{D})$ apoptosis-related proteins were examined by western blot analyses. These are cropped blots, full-length blots of PKC $\delta$ and $\mathrm{pPKC} \delta$ are presented in Suppl. Figure S5. $\beta$-Actin was used as a loading control. N-acetylcysteine, NAC; Rote, rotenone; APO, apocynin; SC, scramble.

\section{AGE-BSA-induced cardiomyocyte apoptosis is through ROS-mediated PKC $\delta$ activation}

To further examine the potential involvement of PKC $\delta$ in the AGE-induced apoptosis, two overexpression plasmids were used: wild type (GFP-PKC $\delta$-WT) and its kinasedead (KD), catalytically inactive $\mathrm{PKC} \delta^{\mathrm{K} 376 \mathrm{R}}$ (GFP-PKC $\delta$ $\mathrm{KD}$, an ATP binding mutant of $\mathrm{PKC} \delta$, lacking kinase activity, as well as this mutant can competitively inhibit the kinase-dependent action of endogenous $\mathrm{PKC} \delta$ ). [3133] (Fig. 4A). As shown in Fig. 4(B \& C) (Suppl. Fig. S4 $\mathrm{B} \& \mathrm{C}$ ), increased cytochrome $C$ protein level, activations of caspase 3 , decreases in the survival protein $\mathrm{Bcl} 2$ and Akt phosphorylation induced by AGE exposure were reversed by a PKC $\delta$ inhibitor, rottlerin (Rott), or PKC $\delta$ siRNA. These results suggest that AGE-BSA-induced apoptosis was associated with $\mathrm{PKC} \delta$ activation. Therefore, cardiac PKC $\delta$ activation by transfection may be used as an AGE exposure model to confirm the effects of AGE on cardiac cells.

As shown in Fig. 4(D) (Suppl. Fig. S4D), the effect of GFP PKC $\delta$-WT overexpression was shown to induce cell apoptosis. As shown in Fig. 4E, at concentrations at 5 $\mu \mathrm{M}$, rottlerin completely inhibited the cell apoptosis. Plasmids overexpressing GFP-PKC $\delta$-WT or GFP-PKC $\delta$ $\mathrm{KD}$ were transfected into cardiac cells. As shown in Fig. 4(F) (Suppl. Fig. S4F), the apoptosis induced by AGEBSA exposure or overexpression of GFP-PKC $\delta$-WT was not observed in cells with GFP-PKC $\delta$-KD overexpression, indicating the involvement of PKC $\delta$ in the AGE-induced cardiac apoptosis.

As shown in Fig. 4(G\&H) (Suppl. Fig. S4 G\&H), we transfected the cells with GFP-PKC $\delta$-WT and GFPPKC $\delta$-KD to confirm the AGE-BSA-induced apoptosis through the activation of $\mathrm{PKC} \delta$ in cardiac cells. Based on the western blot analysis results of fusion protein GFP, its molecular weight shifted from 27 of vector only to 105 of carrying $\mathrm{PKC} \delta$ vectors, including $\mathrm{WT}$ and $\mathrm{KD}$, indicating 
the successful transfection (Fig 4G). AGE-BSA exposure and GFP-PKC $\delta$-WT overexpression induced apoptosis in both NRVM and $\mathrm{H} 9 \mathrm{c} 2$ cells, and these effects were reversed by GFP-PKC $\delta$-KD transfection or the PKC $\delta$ inhibitor rottlerin, respectively. These results suggest that AGE-induced apoptosis is mediated through the activation of PKC $\delta$ in cardiomyocytes.

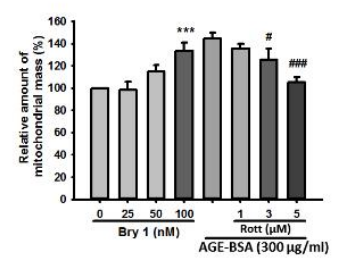

B

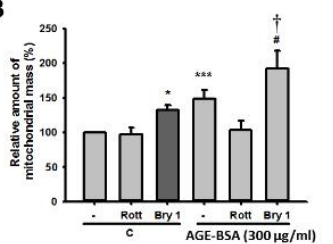

C

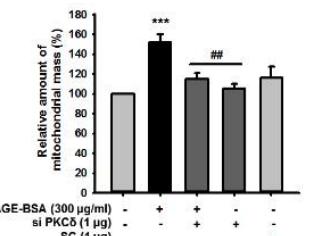

D

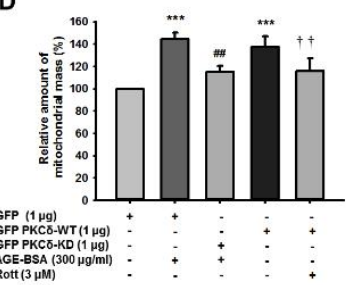

G

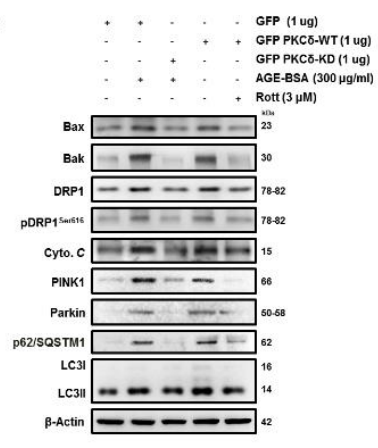

H

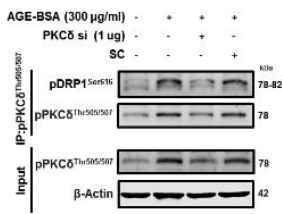

E

Confocal Images

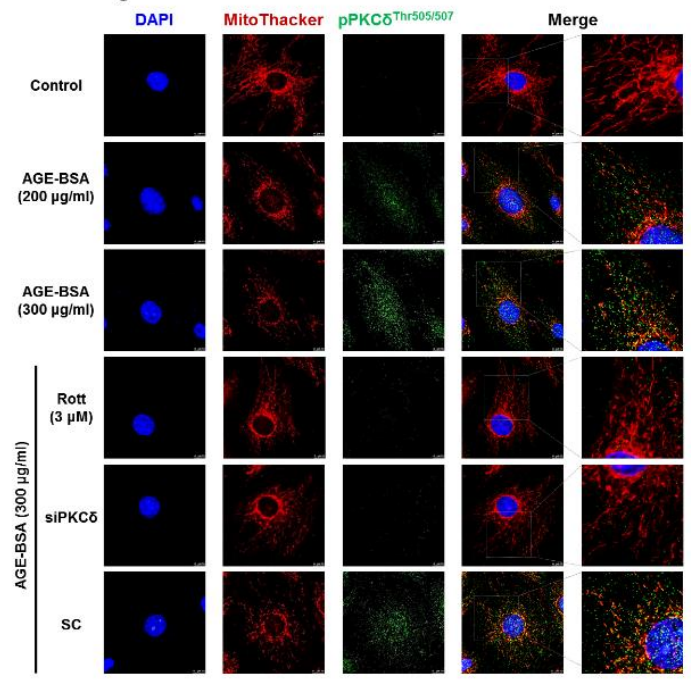

$\mathbf{F}$

Super-Resolution Images

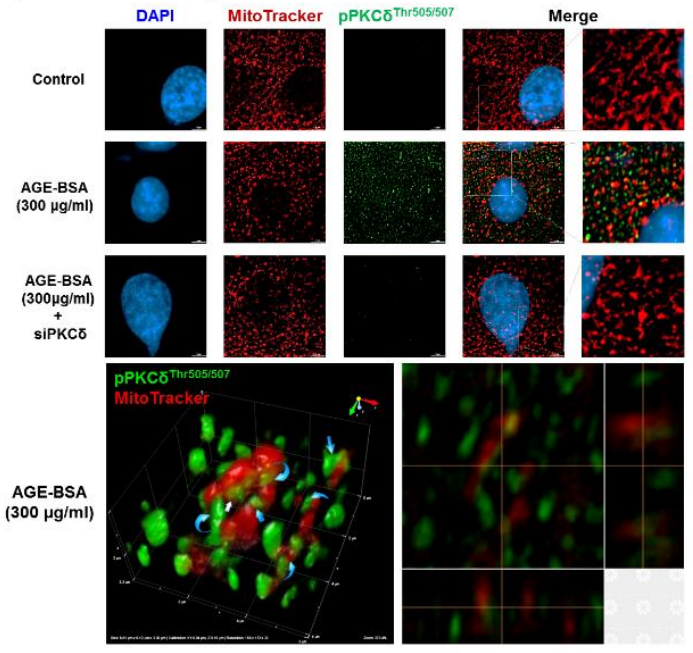

$\mathbf{J}$

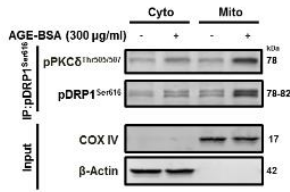

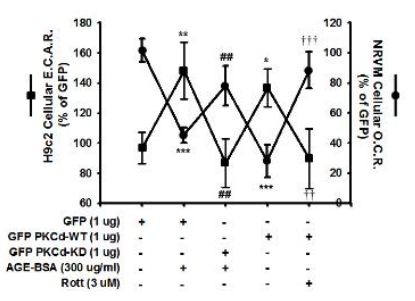

Figure 6. AGE-BSA-induced mitochondria damage and decreased biological function is through $\mathrm{PKC} \delta$ activation and colocalization in cardiac cells. $(A, B)$ Cells were treated with the $\mathrm{PKC} \delta$ activator, bryostatin $1(100 \mathrm{nM})$ or inhibitor, rottlerin, $(3 \mu \mathrm{M})$ for $24 \mathrm{~h}$ following exposure to AGEBSA $(300 \mu \mathrm{g} / \mathrm{ml})$. (C) AGE-BSA-exposed cells were transfected with $\mathrm{PKC} \delta$ siRNA (1 $\mu \mathrm{g})$ for $24 \mathrm{~h}$. (D) Cells were transfected with GFP-PKC $\delta$-WT plus rottlerin or AGE-BSAexposed cells were transfected with GFPPKC $\delta$-KD. Mitochondrial damage was evaluated by mitochondrial mass, which was analyzed by flow cytometry. (E) AGE-BSAtreated cells were administered the inhibitor rottlerin $(3 \mu \mathrm{M})$ or siPKC $\delta$ for $24 \mathrm{~h}$. The mitochondrial fission and colocalization with $\mathrm{PKC} \delta$ were examined by immunefluorescence and analyzed by confocal microscopy. (F) Super resolution images of mitochondria structure in cells were analyzed with similar experimental procedures. Blue, DAPI (4, 6-diamidino-2-phenylindole)stained nuclei; red, MitoTracker Red CMXRos-stained mitochondria. (G) The levels of proteins associated with mitochondrial fission and mitophagy in cells were analyzed with similar experimental procedure. These are cropped blots; fulllength blots are presented in Suppl. Figure S6. Neonatal rat ventricular myocyte (NRVM) and $\mathrm{H} 9 \mathrm{c} 2$ were then analyzed for (H) Cells were treated with AGE-BSA for $24 \mathrm{hr}$ and then transfected with the PKC $\delta$ siRNA $(1 \mu \mathrm{g})$ for $24 \mathrm{hr}$. Cell lysates were immunoprecipitated using antibodies against $\mathrm{pPKC}^{\mathrm{T} 505 / 507}$. Protein expression was detected by immunoblotting. (I) The cytosolic and mitochondrial fractions were isolated and subjected to immunoprecipitation followed by western blot analysis. These are cropped blots; fulllength blots are presented in Suppl. Figure S7. (J) Cellular oxygen consumption rate (O.C.R) and extracellular acidification (E.C.A.R) using an XF24 bioenergetics assay (Seahorse Bioscience, Billerica, MA). Data are expressed as the mean \pm SEM, $n=3$. ${ }^{*} P<0.05, \quad{ }^{* *} P<0.01, \quad{ }^{* * *} P<0.001 \quad$ compared with the control or GFP group, ${ }^{\#} P<0.05$, ${ }^{\#} P<0.01$, \#\# $P<0.001$ compared with the AGE-BSA $(300 \mu \mathrm{g} / \mathrm{mg})$ group, ${ }^{\dagger} P<0.05$ compared with the Bryl-treated group, ${ }^{\dagger} P<0.01$, $P<0.001$ compared with the GFP-PKC $\delta$-WT overexpression group. 
As shown in Fig. 5 (Suppl. Fig. S5) to confirm that ROS mediates the AGE-induced PKC $\delta$ activation to cause cell apoptosis, H9c2 and NRVM cells were treated with AGE-BSA plus the PKC $\delta$ activator Bryostatin 1 (Bry1), the inhibitor Rott, siPKC $\delta$ or the ROS inhibitors N-acetylL-cysteine (NAC), Apocynin (APO) and mitochondrial complex I inhibitor, Rotenone (Rote). Western blotting analyses showed that the AGE-BSA induced PKC $\delta$ phosphorylation was ROS-dependent.

\section{AGE-BSA-induced cardiac mitochondrial dysfunction is mediated through ROS-dependent PKC activation and mitochondrial colocalization}

Since the unique bioenergetic requirements of the heart, the mitochondria are organized throughout the cardiomyocytes with the largest proportional density. Its function is tightly associated with the power provided for the cardiac action. To demonstrate that $\mathrm{PKC} \delta$ plays a role in AGE-BSA-induced mitochondrial damage, we examined cells treated with different doses of Bryostatin 1 (Bry1); the results showed a dose-dependent increase in mitochondrial mass. Furthermore, the increased levels by AGE-BSA were dose-dependently reduced by rottlerin (Fig. 6A). These results were confirmed by the findings that the AGE-BSA-induced mitochondrial mass increase was reduced by rottlerin and further enhanced by Bry1 (Fig. 6B). As shown in Fig. 6(C), the increases in mitochondrial mass by AGE-BSA were reduced following siPKC $\delta$ transfection. As shown in Fig. 6(D), we confirmed these observations by overexpressing GFP PKC $\delta$ wild-type (WT) or its kinase-deficient (KD) mutant in cells. The mitochondrial mass induced by AGE-BSA exposure or GFP PKC $\delta$-WT transfection was reversed by GFP PKC $\delta$-KD transfection or rottlerin, a PKC $\delta$ inhibitor, respectively, indicating that the AGE-BSA-induced mitochondrial mass increase is mediated via $\mathrm{PKC} \delta$ activation.

To further study the role of PKC $\delta$ in AGE-BSA cardiotoxicity, mitochondrial fission was examined by immunofluorescence assays. These results were confirmed with fluorescent dye, Mitotracker Red. As shown in Fig. 6(E), in addition to increased PKC $\delta$ activation, the administration of high doses of AGE-BSA $(200,300 \mu \mathrm{g} / \mathrm{ml})$ could induce PKC $\delta$ activation and mitochondrial fragmentation. Furthermore, the translocation of activated $\mathrm{PKC} \delta$ to the mitochondria is generally accompanied by excessive mitochondrial fragmentation, which was inhibited by the rottlerin and siPKC $\delta$ treatments, indicating that $\mathrm{PKC} \delta$ activation was involved in AGE-BSA-induced mitochondrial dysfunction. Super-resolution microscopy images of the mitochondria are shown in Fig. 6(F). Upon activation of
PKC $\delta$ by AGE-BSA exposure, the mitochondrial network changed its shape with elongation and swell, as well as aggregated fragmented mitochondria were observed and this was inhibited by the treatments of rotterlin and siPKC $\delta$. These data suggest that AGE-BSA-induced mitochondrial dysfunction, such as mitochondrial fission, is through $\mathrm{PKC} \delta$ colocalization and activation.

Drp1 (dynamin-related protein 1) is a mitochondrial dynamic regulator that promotes mitochondria-mediated constriction to induce mitochondrial fission and apoptosis. Its phosphorylation site, serine 616 (S616), can be phosphorylated by $\mathrm{PKC} \delta$, thus increasing mitochondrial fragmentation [18]. During apoptosis, DRP1 with Bax and Bax foci accumulate in the mitochondria and promote substantial mitochondrial fission to further enhance caspase activation [30, 34]. Therefore, Drp1 plays a central role in this process [34-37]. Mitophagy is the selective engulfment of mitochondria by autophagosomes and their subsequent catabolism by lysosomes [38]. It often occurs to defective mitochondria following damage or stress. Previous reports indicated PINK1 and Parkin are involved in the regulation of mitochondrial dynamics [39]. The mitochondrial accumulation of proteins that are polyubiquitinated recruits the ubiquitin- and LC3-binding adaptor protein p62/SQSTM1 after Parkin translocation [40]. To assess the effect of AGE-mediated PKC $\delta$ activation on cardiac cells, we reduced the enhanced levels of these proteins mediated by $\mathrm{PKC} \delta$-WT overexpression and AGE-BSA exposure using rottlerin and $\mathrm{PKC} \delta$-KD overexpression, respectively. As shown in Fig. 6(G) (Suppl. Fig. S6), these data suggest that PKC $\delta$ is a target of AGE-BSA, which results in abnormal mitochondrial function, initiation of apoptosis and cardiotoxicity.

Because siPKC $\delta$ abolished PKC $\delta$ co-localized to the mitochondria (Fig. 6E\&F) in cardiomyocytes, we next determined whether Drp1 and PKC $\delta$ interact directly. In the previous study, it has been known that Drp1 is phosphorylated by PKC $\delta$ and the phospho-Drp 1 is formed a complex with $\mathrm{PKC} \delta$. The activated $\mathrm{PKC} \delta$ is translocated to mitochondria through the interaction of the mitochondrial outer membrane protein Fis1 with phospho-Drp1 in neuron suffered oxidative stress [18]. We further study whether the role of the phospho-Drp1 is translocated to the mitochondria and is co-localized with activated $\mathrm{PKC} \delta$ on the mitochondria in cardiomyocytes. As shown in Fig. 7(H) (Suppl. Fig. S7), we found that siPKC $\delta$ treatment reduces PKCd binds to DRP1 protein levels following AGE-BSA exposure, suggesting that AGE-BSA promotes DRP1 protein activated by elevated PKC $\delta$ phosphorylated. As shown in Fig. 7(I) (Suppl. Fig. S7), the cytosolic and mitochondrial fractions were isolated and subjected to immunoprecipitation further 
revealed that ectopic PKC $\delta$ was associated with DRP1. These results suggested that the phospho-Drp1/ phospho$\mathrm{PKC} \delta$ complex is enriched in the isolated mitochondria.

To assess AGE-BSA-induced changes in the mitochondria function of cardiomyocytes, metabolic capacity and extracellular acidification were evaluated. Neonatal ventricular cardiomyocytes were treated with AGE-BSA at $300 \mu \mathrm{g} / \mathrm{ml}$ for $24 \mathrm{~h}$ or $\mathrm{PKC} \delta$-WT transfection, followed by $\mathrm{PKC} \delta-\mathrm{KD}$ overexpression or rottlerin, respectively. Then, we measured the rates of cellular oxygen consumption (OCR) and extracellular acidification (ECAR) using a Seahorse XF24 flux analyzer. As shown in Fig. 7(J), the data from both AGE-
BSA-exposure and $\mathrm{PKC} \delta \mathrm{WT}$ overexpression were similar, and the decreased cellar OCR and increased ECAR following AGE-BSA exposure and PKC $\delta$ WT overexpression were reversed by $\mathrm{PKC} \delta$-KD transfection and rottlerin treatment, respectively, suggesting that $\mathrm{PKC} \delta$ regulates mitochondrial energy and redox metabolism in cardiomyocytes exposed to AGE-BSA. These findings indicate that the AGE-BSA-induced mitochondrial biological dysfunction is mediated through $\mathrm{PKC} \delta$ activation.

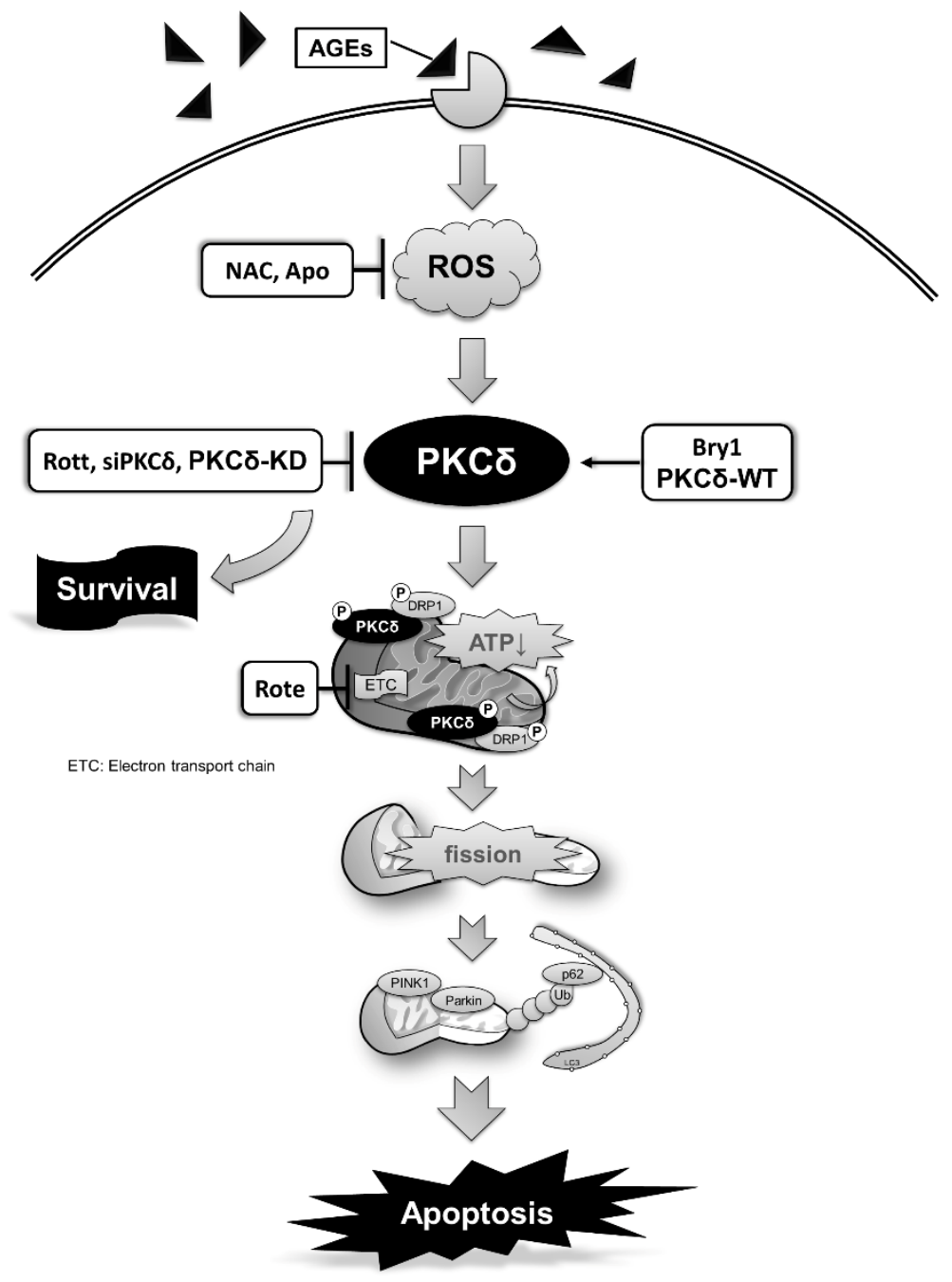

Figure 7. Molecular events of ROS-dependent PKC $\delta$ activation involved in the AGE-BSAinduced cardiomyocyte apoptosis. $\mathrm{PKC} \delta$ activation is involved in the regulation of AGEBSA-induced cell apoptosis via ROS production and may play a key role in the development of cardiac mitochondrial dysfunction in rats with diabetes or obesity. 


\section{DISCUSSION}

DM is one of the leading causes of death worldwide. Hyperglycemia is considered the principal cause of diabetic complications [7]. The increased level of blood glucose enhances the formation of sugar-derived circulatory substances called AGEs. AGEs production and accumulation are often associated with an increase of ROS and linked to multiple sequelae, such as diabetic cardiomyopathy [41, 42]. Therefore, the effects of AGE accumulation may have an impact with heart failure. In this study, we investigated the role of PKC $\delta$ signaling in regulating cardiomyocyte apoptosis in response to AGEs in both cell and animal models. Our results (Fig. 7) demonstrate that the ROS-dependent PKC $\delta$ activation by AGE-BSA triggered mitochondrial dysfunction and further led to cardiac cell death, supporting the hypothesis that $\mathrm{PKC} \delta$ exerts as an important regulator of mitochondrial function and apoptosis in cardiomyocytes following AGE-BSA exposure.

PKC $\delta$, a member of a novel class of protein kinase $C$, contains amino-terminal regulatory and carboxyl-terminal catalytic domains separated by a flexible hinge region. $\mathrm{PKC} \delta$ is shown to regulate a variety of biological functions in different cell types, including proliferation, survival, and apoptosis. PKC $\delta$ is also reported to involve invasion and metastasis in cancer cells [43-45]. Notably, recent studies suggest $\mathrm{PKC} \delta$ mediated the regulation of mitochondrial fission in neuropathogenesis [18, 31]. $\mathrm{PKC} \delta$ is activated for phosphorylation by a variety of stimuli [11], such as ROS, anti-cancer agents, ultraviolet radiation [46], growth factors, and cytokines [47]. There are several phosphorylation sites in PKC $\delta$ modulated in a cell type and stimulus-specific manner. The phosphorylation of different sites contributions to different results of $\mathrm{PKC} \delta$ activation[48]. In addition, the threonine phosphorylation in the activation loop segment of C-terminal is required for its kinase activity [13, 49]. Among the stimuli, the $\mathrm{H}_{2} \mathrm{O}_{2}$ treatment in human cells, tyrosine and threonine phosphorylations are observed to result in mitochondrial dysfunction, and threonine 505 has also been detected in response to $\mathrm{H}_{2} \mathrm{O}_{2}$-induced apoptosis $[48,50]$. The phosphorylation at catalytic fragment demonstrated the result of cell death which is associated with the caspase-3-dependent cleavage of $\mathrm{PKC} \delta$. This is in consistent with our results (Fig. 4F) that overexpression of $\mathrm{PKC} \delta-\mathrm{KD}$, which is mutated at $\mathrm{PKC} \delta^{\mathrm{K} 376 \mathrm{R}}$ to cause catalytical inactivation, resulted in the inhibition of apoptosis. Furthermore, translocation of PKC $\delta$ to the mitochondria, cytoplasm, nucleus and other cellular organelles after phosphorylation initiates programmed cell death [11, 14, 51-54]. In our study, phosphorylation of PKC $\delta$ at Threonine 505 was observed in cells and colocalization with mitochondria following AGE exposure. At the same time, cell apoptosis and mitochondrial dysfunction were also observed. Additionally, using AGE exposure to investigate the involvement of $\mathrm{PKC} \delta$, we also set up a PKC $\delta$-WT overexpression model to represent AGE effect, and rottlerin was applied as a PKC $\delta$ inhibitor which has been shown to have many off-target effects. However, the selections for PKC $\delta$ inhibitory action in the present study include siRNA and $\mathrm{PKC} \delta$-KD overexpression (with a dominant negative activity). The treatments of PKC $\delta$ siRNA showed the same results in experiments, such as Fig. 4C, Fig. 5(A\&C), Fig. $6 \mathrm{C}$ and the images in Fig. $6(\mathrm{E} \& \mathrm{~F})$, and the treatments of $\mathrm{PKC} \delta-\mathrm{KD}$ overexpression showed the similar results in Fig. $4(\mathrm{G} \& \mathrm{H})$, Fig. $6(\mathrm{D} \& \mathrm{G} \& \mathrm{H})$. Therefore, the off-target property of rottlerin is not able to limit the conclusion being made.

Mitochondria provide cellular energy and are critical for cell survival; its morphology is regulated by a balance between fission and fusion which is associated with the development of apoptosis $[18,19]$. The quality control by mitophagy is the distinction between damaged and healthy mitochondria. In our study, using the antibody of phosphorylated PKC $\delta$ and phosphorylated Drp-1 to detect the effect of PKC $\delta$ activation on mitochondrial morphology, the data demonstrated that $\mathrm{PKC} \delta$-induced mitochondrial fragmentation may be associated with a disruption of mitochondrial fusion. And mitophagy is regulated by PINK1 and parkin proteins; the parkin recruitment to depolarized mitochondria promotes their degradation. Autophagy adaptor p62/SQSTM1 might also be involved in mitophagy as it has ubiquitin- and LC3binding domain and has a role in recruiting autophagosomes to ubiquitylated protein aggregates [38, 39]. Indeed, it was observed that treatment with a $\mathrm{PKC} \delta$ inhibitor or $\mathrm{PKC} \delta-\mathrm{KD}$ reduced Drp1 phosphorylation induced by $\mathrm{PKC} \delta$-WT overexpression or AGE-BSA exposure, respectively (Fig. 6G), supporting our hypothesis that AGE-BSA-induced Drp1 phosphorylation is likely to be mediated through PKC $\delta$ activation. In addition to the selective removal of damaged mitochondria, mitophagy might also require regulating mitochondrial numbers to changing cellular metabolic needs.

Furthermore, ligand engagement of RAGE by AGEs results in the production of cellular ROS [55]. A previous study [56] showed that high glucose-induced cellular ROS generation in human peritoneal mesothelial cells (HPMC) via activation of nicotinamide adenine dinucleotide phosphate (NADPH) oxidase, reducing the rate of mitochondrial metabolism, suggesting that ROS and mitochondrial dysfunction are important pathogenetic mediators of diabetic complications. In Lee's study [20], 
the increase of mitochondrial mass and intracellular ROS levels accompanied by up-regulation of $\mathrm{PKC} \delta$ phosphorylation was observed in human osteosarcoma 143B cells following $\mathrm{H}_{2} \mathrm{O}_{2}$ treatment. Therefore, $\mathrm{PKC} \delta$ may play a role in the $\mathrm{H}_{2} \mathrm{O}_{2}$-induced increase of mitochondrial mass, which was completely inhibited by a $\mathrm{PKC} \delta$ inhibitor, rottlerin. These data indicate that mitochondrial targeting of $\mathrm{PKC} \delta$ is required for the response of cells to oxidative stress. Moreover, it is also reported that $\mathrm{PKC} \delta$ activity was increased by phosphorylation of threonine 505/507 and tyrosine $313 / 311$ in response to oxidative stress [20, 48, 57]. Another study [58] indicated that phosphorylation of T505 in the activation loop in the hydrophobic C-terminus appears to be important for PKC $\delta$ activation. Additionally, activation of $\mathrm{PKC} \delta$ is required for its mitochondrial localization and resulted in cytochrome $c$ release, caspase activation, and cardiac apoptosis [14, 15, 20]. In our study, firstly, the results of the western blot analyses and IHC staining using $\mathrm{PKC} \delta$ T505/507 phosphorylation antibodies showed PKC $\delta$ activation in the hearts of animals with DM and a high-fat diet. The analysis of Seahorse XF24 flux analyzer demonstrated that AGEBSA treatment reduced mitochondrial functions, which were reversed by the PKC $\delta$ inhibitor. Secondly, superresolution microscopy images clearly indicated that the colocalization of activated $\mathrm{PKC} \delta$ and mitochondria, and AGE exposure-induced mitochondrial fission were ameliorated by the PKC $\delta$ siRNA treatment. Therefore, our evidence strongly supports the hypothesis that AGEs enhanced PKC $\delta$ activation and its colocalization to mitochondria, further promoting mitochondrial fission, and reducing its biological function which results in cell death, leading to heart failure.

The heart is an organ requesting the highest amount of ATP. It predominantly relies on mitochondrial metabolism to provide the energy needed to pump blood to entire body. In addition, the physiology and oxidative stress-induced cellular damage from mitochondria are considered to constitute a central event in apoptosis [19]. Therefore, heart function is closely related to the mitochondrial action. The failure of mitochondria function contributes to the development of cardiac failure. On the other hand, AGEs have been shown to impair respiratory function and overproduction of ROS, which facilitates the production of mitochondrial superoxide contributing to tissue damage in diabetic patients $[10,59$, $60]$. Here, we provide the evidence of the involvement of mitochondrial dysfunction and oxidative stress in the cellular toxicity produced by AGE-BSA. Our findings demonstrated that $\mathrm{PKC} \delta$ is a critical regulator of mitochondrial fission in diabetic cardiomyocytes. We conclude that cardiac ROS-dependent PKC $\delta$ activation can induce its colocalization with mitochondria, Drp1dependent mitochondria fission and fragmentation and reduced biological functions resulting in cardiac failure. Therefore, the development of new therapeutic strategies that is capable of preventing AGE induced-ROSdependent $\mathrm{PKC} \delta$ activation may be a promising treatment for cardiomyopathy caused by increased levels of AGEs.

\section{Supplemental data}

Supplemental data are available at www.aginganddisease.org/EN/10.14336/AD.2017.0924

\section{Acknowledgments}

This study is supported in part by Taiwan Ministry of Health and Welfare Clinical Trial and Research Center of Excellence (MOHW106-TDU-B-212-113004); China Medical University (CMU105-S-32); Ministry of Science and Technology (MOST 106-2320-B-039-038).

\section{Competing Interests}

The authors declare that they have no competing interests.

\section{References}

[1] Cai L, Li W, Wang G, Guo L, Jiang Y, Kang YJ (2002). Hyperglycemia-induced apoptosis in mouse myocardium: mitochondrial cytochrome C-mediated caspase-3 activation pathway. Diabetes, 51: 1938-1948

[2] Dyntar D, Eppenberger-Eberhardt M, Maedler K, Pruschy M, Eppenberger HM, Spinas GA, et al. (2001). Glucose and palmitic acid induce degeneration of myofibrils and modulate apoptosis in rat adult cardiomyocytes. Diabetes, 50: 2105-2113

[3] Huang C-Y, Lee S-D (2012). Possible pathophysiology of heart failure in obesity: Cardiac apoptosis. BioMedicine, 2: 36-40

[4] Thallas-Bonke V, Thorpe SR, Coughlan MT, Fukami K, Yap FY, Sourris KC, et al. (2008). Inhibition of NADPH oxidase prevents advanced glycation end productmediated damage in diabetic nephropathy through a protein kinase $\mathrm{C}$-alpha-dependent pathway. Diabetes, 57: 460-469

[5] Zhang M, Kho AL, Anilkumar N, Chibber R, Pagano PJ, Shah AM, et al. (2006). Glycated proteins stimulate reactive oxygen species production in cardiac myocytes: involvement of Nox2 (gp91phox)-containing NADPH oxidase. Circulation, 113: 1235-1243

[6] Chen S-Y, Hsu Y-M, Lin Y-J, Huang Y-C, Chen C-J, Lin $\mathrm{W}-\mathrm{D}$, et al. (2016). Current concepts regarding developmental mechanisms in diabetic retinopathy in Taiwan. BioMedicine, 6: 1-8

[7] Manigrasso MB, Juranek J, Ramasamy R, Schmidt AM (2014). Unlocking the biology of RAGE in diabetic 
microvascular complications. Trends in endocrinology and metabolism: TEM, 25: 15-22

[8] Yan SF, Ramasamy R, Schmidt AM (2010). The RAGE axis: a fundamental mechanism signaling danger to the vulnerable vasculature. Circulation research, 106: 842853

[9] Ou HC, Tzang BS, Chang MH, Liu CT, Liu HW, Lii CK, et al. (2010). Cardiac contractile dysfunction and apoptosis in streptozotocin-induced diabetic rats are ameliorated by garlic oil supplementation. J Agric Food Chem, 58: 10347-10355

[10] Kuo WW, Wang WJ, Tsai CY, Way CL, Hsu HH, Chen LM (2013). Diallyl trisufide (DATS) suppresses high glucose-induced cardiomyocyte apoptosis by inhibiting JNK/NFkappaB signaling via attenuating ROS generation. International journal of cardiology, 168: 270280

[11] Brodie C, Blumberg PM (2003). Regulation of cell apoptosis by protein kinase c delta. Apoptosis, 8: 19-27

[12] Basu A, Pal D (2010). Two faces of protein kinase Cdelta: the contrasting roles of PKCdelta in cell survival and cell death. TheScientificWorldJournal, 10: 2272-2284

[13] Zhao M, Xia L, Chen GQ (2012). Protein kinase c delta in apoptosis: a brief overview. Archivum immunologiae et therapiae experimentalis, 60: 361-372

[14] Dave KR, Bhattacharya SK, Saul I, DeFazio RA, Dezfulian C, Lin HW, et al. (2011). Activation of Protein Kinase C Delta following Cerebral Ischemia Leads to Release of Cytochrome $\mathrm{C}$ from the Mitochondria via Bad Pathway. PloS one, 6: e22057

[15] Mochly-Rosen D, Das K, Grimes KV (2012). Protein kinase $\mathrm{C}$, an elusive therapeutic target? Nature reviews. Drug discovery, 11: 937-957

[16] Churchill EN, Mochly-Rosen D (2007). The roles of $\mathrm{PKC} \delta$ and $\varepsilon$ isoenzymes in the regulation of myocardial ischaemia/reperfusion injury. Biochem Soc Trans, 35: 1040-1042

[17] Yamamoto T, Matsuzaki H, Konishi H, Ono Y, Kikkawa $\mathrm{U}(2000)$. $\mathrm{H}(2) \mathrm{O}(2)$-induced tyrosine phosphorylation of protein kinase cdelta by a mechanism independent of inhibition of protein-tyrosine phosphatase in $\mathrm{CHO}$ and COS-7 cells. Biochemical and biophysical research communications, 273: 960-966

[18] Qi X, Disatnik MH, Shen N, Sobel RA, Mochly-Rosen D (2011). Aberrant mitochondrial fission in neurons induced by protein kinase $\mathrm{C}\{$ delta $\}$ under oxidative stress conditions in vivo. Molecular biology of the cell, 22: 256-265

[19] Yu T, Sheu SS, Robotham JL, Yoon Y (2008). Mitochondrial fission mediates high glucose-induced cell death through elevated production of reactive oxygen species. Cardiovascular research, 79: 341-351

[20] Lee CF, Chen YC, Liu CY, Wei YH (2006). Involvement of protein kinase $\mathrm{C}$ delta in the alteration of mitochondrial mass in human cells under oxidative stress. Free radical biology \& medicine, 40: 2136-2146

[21] Geraldes P, King GL (2010). Activation of protein kinase $\mathrm{C}$ isoforms and its impact on diabetic complications. Circulation research, 106: 1319-1331
[22] Palaniyandi SS, Sun L, Ferreira JC, Mochly-Rosen D (2009). Protein kinase $C$ in heart failure: a therapeutic target? Cardiovascular research, 82: 229-239

[23] Huang CY, Kuo WW, Yeh YL, Ho TJ, Lin JY, Lin DY, et al. (2014). ANG II promotes IGF-IIR expression and cardiomyocyte apoptosis by inhibiting HSF1 via JNK activation and SIRT1 degradation. Cell death and differentiation, 21: 1262-1274

[24] Forbes JM, Yee LTL, Vicki Thallas ML, Candido R, Jandeleit-Dahm KA, Thomas MC, et al. (2004). Advanced Glycation End Product Interventions Reduce Diabetes-Accelerated Atherosclerosis. Diabetes, 53: 1813-1823

[25] Tomoko Mitsuhashi HV, H.W. Founds, Yong Ming Li (1997). Standardizing the immunological measurement of advanced glycation endproducts using normal human serum. J Immunol Methods, 207: 79-88

[26] Yu L, Zhao Y, Xu S, Ding F, Jin C, Fu G, et al. (2013). Advanced Glycation End Product (AGE)-AGE Receptor (RAGE) System Upregulated Connexin43 Expression in Rat Cardiomyocytes via PKC and Erk MAPK Pathways. International journal of molecular sciences, 14: 22422257

[27] Cheng SY, Yang YC, Ting KL, Wen SY, Viswanadha VP, Huang CY, et al. (2016). Lactate dehydrogenase downregulation mediates the inhibitory effect of diallyl trisulfide on proliferation, metastasis, and invasion in triple-negative breast cancer. Environmental toxicology: 1390-1398

[28] Chen CL, Hsieh YT, C. CH (2007). Phosphorylation of adducin by protein kinase $\mathrm{Cd}$ promotes cell motility. $\mathrm{J}$ Cell Sci, Pt 7: 1157-1167

[29] Cheng YC, Kuo WW, Wu HC, Lai TY, Wu CH, Hwang JM, et al. (2009). ZAK induces MMP-2 activity via $\mathrm{JNK} / \mathrm{p} 38$ signals and reduces MMP-9 activity by increasing TIMP-1/2 expression in H9c2 cardiomyoblast cells. Molecular and cellular biochemistry, 325: 69-77

[30] Tanaka A, Youle RJ (2008). A chemical inhibitor of DRP1 uncouples mitochondrial fission and apoptosis. Molecular cell, 29: 409-410

[31] Latchoumycandane C, Anantharam V, Kitazawa M, Yang Y, Kanthasamy A, Kanthasamy AG (2005). Protein kinase $\mathrm{C}$ delta is a key downstream mediator of manganese-induced apoptosis in dopaminergic neuronal cells. J Pharmacol Exp Ther, 313: 46-55

[32] Anantharam V, Kitazawa M, Wagner J, Kaul S, Kanthasamy AG (2002). Caspase-3-Dependent Proteolytic Cleavage of Protein Kinase Cd Is Essential for Oxidative Stress-Mediated Dopaminergic Cell Death after Exposure to Methylcyclopentadienyl Manganese Tricarbonyl. J Neurosci, 22: 1738-1751

[33] Guo J, Cong L, Rybin VO, Gertsberg Z, Steinberg SF (2010). Protein kinase $\mathrm{C}-\{$ delta $\}$ regulates the subcellular localization of $\mathrm{Shc}$ in $\mathrm{H} 2 \mathrm{O} 2$-treated cardiomyocytes. Am J Physiol Cell Physiol, 299: C770778

[34] Youle RJ, Karbowski M (2005). Mitochondrial fission in apoptosis. Nature reviews. Molecular cell biology, 6: 657-663 
[35] van der Bliek AM (2009). Fussy mitochondria fuse in response to stress. EMBO J, 28: 1533-1534

[36] van der Bliek AM, Shen Q, Kawajiri S (2013). Mechanisms of mitochondrial fission and fusion. Cold Spring Harbor perspectives in biology, 5: a011072

[37] Sheridan C, Martin SJ (2010). Mitochondrial fission/fusion dynamics and apoptosis. Mitochondrion, 10: 640-648

[38] Chourasia AH, Boland ML, Macleod KF (2015). Mitophagy and cancer. Cancer Metab, 3: 4

[39] Imai Y (2012). Mitochondrial Regulation by PINK1Parkin Signaling. ISRN Cell Biology, 2012: 1-15

[40] Jin SM, Youle RJ (2012). PINK1 - and Parkin-mediated mitophagy at a glance. J Cell Sci, 125: 795-799

[41] Meerwaldt R, Lutgers HL, Links TP, Graaff R, Baynes JW, Gans RO, et al. (2007). Skin autofluorescence is a strong predictor of cardiac mortality in diabetes. Diabetes care, 30: 107-112

[42] Fox CS, Coady S, Sorlie PD, D'Agostino RB, Pencina MJ, Vasan RS, et al. (2007). Increasing cardiovascular disease burden due to diabetes mellitus: the Framingham Heart Study. Circulation, 115: 1544-1550

[43] Reno EM, Haughian JM, Dimitrova IK, Jackson TA, Shroyer KR, Bradford AP (2008). Analysis of Protein Kinase C Delta (PKC $\delta$ ) Expression in Endometrial Tumors. Hum Pathol, 39: 21-29

[44] Chen Z, Forman LW, Williams RM, Faller DV (2014). Protein kinase C-delta inactivation inhibits the proliferation and survival of cancer stem cells in culture and in vivo. BMC Cancer, 14: 90

[45] Chen Z FL, Williams RM, Faller DV (2014). Protein kinase $\mathrm{C}-\delta$ inactivation inhibits the proliferation and survival of cancer stem cells in culture and in vivo. BMC Cancer, 14: 90

[46] Liu CY, Lee CF, Wei YH (2009). Activation of PKCdelta and ERK1/2 in the sensitivity to UV-induced apoptosis of human cells harboring $4977 \mathrm{bp}$ deletion of mitochondrial DNA. Biochim Biophys Acta, 1792: 783790

[47] Ren J, Wang Q, Morgan S, Si Y, Ravichander A, Dou C, et al. (2014). Protein kinase C-delta (PKCdelta) regulates proinflammatory chemokine expression through cytosolic interaction with the NF-kappaB subunit p65 in vascular smooth muscle cells. J Biol Chem, 289: 90139026

[48] Konishi H, Yamauchi E, Taniguchi H, Yamamoto T, Matsuzaki H, Takemura Y, et al. (2001). Phosphorylation sites of protein kinase $\mathrm{C} \delta$ in $\mathrm{H} 2 \mathrm{O} 2$-treated cells and its activation by tyrosine kinase in vitro. Proc Natl Acad Sci U S A., 98: 6587-6592

[49] Steinberg SF (2008). Structural Basis of Protein Kinase
C Isoform Function. Physiol Rev, 88: 1341-1378

[50] Sabri A (2002). Dual Actions of the Galphaq Agonist Pasteurella multocida Toxin to Promote Cardiomyocyte Hypertrophy and Enhance Apoptosis Susceptibility. Circ Res, 90: 850-857

[51] Dehghani H, Reith C, Hahnel AC (2005). Subcellular localization of protein kinase $\mathrm{C}$ delta and epsilon affects transcriptional and post-transcriptional processes in fourcell mouse embryos. Reproduction, 130: 453-465

[52] DeVries TA, Neville MC, Reyland ME (2002). Nuclear import of $\mathrm{PKC} \delta$ is required for apoptosis: identification of a novel nuclear import sequence. EMBO J, 21: 6050 6060

[53] Sun F, Kanthasamy A, Song C, Yang Y, Anantharam V, Kanthasamy AG (2008). Proteasome inhibitor-induced apoptosis is mediated by positive feedback amplification of PKCdelta proteolytic activation and mitochondrial translocation. Journal of cellular and molecular medicine, 12: 2467-2481

[54] Yoshida K (2007). PKCdelta signaling: mechanisms of DNA damage response and apoptosis. Cellular signalling, 19: $892-901$

[55] Wei Q, Ren X, Jiang Y, Jin H, Liu N, Li J (2013). Advanced glycation end products accelerate rat vascular calcification through RAGE/oxidative stress. BMC cardiovascular disorders, 13: 13

[56] Lee HB, Yu MR, Song JS, Ha H (2004). Reactive oxygen species amplify protein kinase $\mathrm{C}$ signaling in high glucose-induced fibronectin expression by human peritoneal mesothelial cells. Kidney Int, 65: 1170-1179

[57] Kato K, Yamanouchi D, Esbona K, Kamiya K, Zhang F, Kent KC, et al. (2009). Caspase-mediated protein kinase $\mathrm{C}$ delta cleavage is necessary for apoptosis of vascular smooth muscle cells. Am J Physiol Heart Circ Physiol, 297: H2253-H2261

[58] Lee SJ, Kang JH, Choi SY, Suk KT, Kim DJ, Kwon OS (2013). PKCdelta as a regulator for TGFbeta1-induced alpha-SMA production in a murine nonalcoholic steatohepatitis model. PloS one, 8: e55979

[59] Tsai CY, Wen SY, Shibu MA, Yang YC, Peng H, Wang $\mathrm{B}$, et al. (2015). Diallyl trisulfide protects against high glucose-induced cardiac apoptosis by stimulating the production of cystathionine gamma-lyase-derived hydrogen sulfide. International journal of cardiology, 195: $300-310$

[60] Tsai KH, Wang WJ, Lin CW, Pai P, Lai TY, Tsai CY, et al. (2012). NADPH oxidase-derived superoxide anioninduced apoptosis is mediated via the JNK-dependent activation of NF-kappaB in cardiomyocytes exposed to high glucose. J Cell Physiol, 227: 1347-1357 